\title{
WP 20_09
}

\author{
Matilde Bombardini \\ University of British Columbia, CIFAR, NBER \\ and \\ The Rimini Centre for Economic Analysis
}

Giovanni Gallipoli

University of British Columbia

Germán Pupato

University of British Columbia

\section{SKILL DISPERSION AND TRADE FLOWS}

\section{Copyright belongs to the author. Small sections of the text, not exceeding three paragraphs, can be used} provided proper acknowledgement is given.

The Rimini Centre for Economic Analysis (RCEA) was established in March 2007. RCEA is a private, nonprofit organization dedicated to independent research in Applied and Theoretical Economics and related fields. RCEA organizes seminars and workshops, sponsors a general interest journal The Review of Economic Analysis, and organizes a biennial conference: Small Open Economies in the Globalized World (SOEGW). Scientific work contributed by the RCEA Scholars is published in the RCEA Working Papers series.

The views expressed in this paper are those of the authors. No responsibility for them should be attributed to the Rimini Centre for Economic Analysis. 


\title{
Skill Dispersion and Trade Flows
}

\author{
Matilde Bombardini, Giovanni Gallipoli† and Germán Pupato
}

June 2009

\begin{abstract}
Is skill dispersion a source of comparative advantage? While it is established that a country's aggregate endowment of human capital is an important determinant of comparative advantage, this paper investigates whether the distribution of skills in the labor force can play a role in the determination of trade flows. We develop a multi-country, multi-sector model of trade in which comparative advantage derives from (i) differences across sectors in the complementarity of workers' skills, (ii) the dispersion of skills in the working population. First, we show how higher dispersion in human capital can trigger specialization in sectors characterized by higher substitutability among workers' skills. We then use industry-level bilateral trade data to show that human capital dispersion, as measured by a standard international metric, has a significant effect on trade flows. We find that the effect is of a magnitude comparable to that of aggregate endowments. The result is robust to the introduction of several controls for other proximate causes of comparative advantage.
\end{abstract}

JEL Classification codes: F12, F16, J82.

We would like to thank Paul Beaudry, David Green, Patrick Francois, Thomas Lemieux, Vadim Marmer, Francesco Trebbi, Jonathan Vogel and seminar participants at CIFAR for helpful comments.

*University of British Columbia, CIFAR, NBER and RCEA.

${ }^{\dagger}$ University of British Columbia and RCEA.

${ }^{\ddagger}$ University of British Columbia 


\section{Introduction}

One of the mainstays of the theory of comparative advantage is that countries' factor endowments determine the pattern of trade. An established theoretical framework, the Heckscher-OhlinSamuelson factor proportion theory, and numerous related empirical studies ${ }^{1}$ identify quantities such as the stocks of human and physical capital of countries as primary sources of comparative advantage. In this paper we provide evidence supporting an alternative, and empirically sizeable, source of comparative advantage: the dispersion of human capital in the working population. ${ }^{2}$

Why would the distribution of human capital matter for specialization and trade? We argue that sectors vary in the degree of complementarity among the skills of workers employed. We conjecture that for some sectors, for example engine and turbine manufacturing, it is essential to employ workers of similar skills at every stage of production, ${ }^{3}$ while for other sectors, like computer or apparel, the output of a team is sensitive to the presence of extremely skilled individuals, even if some stages of production are left to workers with lower human capital. Given that sectoral technologies may vary in this dimension, we investigate the hypothesis that countries with greater skill dispersion specialize in sectors characterized by higher substitutability among workers' skills.

The idea that skill dispersion may lead to specialization has been the object of work by Grossman and Maggi (2000), henceforth GM, who show that, in a two-country, two-sector model, the country with a relatively more dispersed skill distribution may specialize in the sector that benefits from matching workers of different skill levels. This paper builds upon GM's insight, making two contributions. First, it proposes a multi-country, multi-sector model where skill dispersion gen-

\footnotetext{
${ }^{1}$ Among others, Romalis (2004), testing the predictions of the theory about commodity trade, and Bowen et al. (1987), Trefler (1993), Trefler (1995), and Davis and Weinstein (2001), testing the factor content predictions of the theory.

${ }^{2}$ Human capital is determined by many factors, among which formal education, family upbringing, underlying ability and on-the-job training. Throughout this paper we refer to human capital or skills, terms that we use interchangeably, as a set of attributes that are of productive use in the workplace.

${ }^{3}$ Using the terminology of Kremer (1993), these sectors exhibit an O-ring technology.
} 
erates testable implications for the pattern of international trade. Second, it provides empirical evidence that diversity is in fact a strong determinant of specialization. We present evidence that the dispersion of human capital matters as much as its stock in determining comparative advantage, a novel finding to the best of our knowledge.

A first glance at the data reveals that cross-country differences in skill dispersion are considerably larger than differences in the average skills of workers. We employ the distribution of scores in the International Adult Literacy Survey (IALS), an internationally comparable measure of work-related skills, as a proxy for the distribution of human capital. Figure 1 reports the mean and standard deviation of IALS during 1994-1998. The coefficient of variation of the standard deviation of log-scores is an order of magnitude larger than that of the average log-scores.

The reasons why countries at similar stages of development differ in their skill distribution are beyond the scope of this study; ${ }^{4}$ such differences may be due to the degree of centralization in the education system and curricular control (Stevenson and Baker, 1991), the existence of elite schools, sorting and segregation, ${ }^{5}$ early tracking, ${ }^{6}$ local school financing (Benabou, 1996) and the share of private and public schools (Takii and Tanaka, 2009). ${ }^{7}$

The first contribution of this paper is a theoretical framework that allows us to investigate the relevance of skill dispersion for comparative advantage in a multi-sector multi-country environment. This is related but distinct from the one presented in GM. They show that, if skills are perfectly observable and the production function is symmetric, CRS and supermodular in the skills of work-

\footnotetext{
${ }^{4}$ What is not beyond the scope of this study is a discussion of how the endogeneity of skill dispersion might affect our empirical results. See Section 4.4.

${ }^{5}$ The existence of peer effects, as documented for example by Hanushek et al. (2003) and Hoxby and Building (2000), implies that segregation and sorting might result in even higher inequality of educational outcomes. An example of this amplification mechanism is provided by Friesen and Krauth (2007).

${ }^{6}$ Tracking refers to the practice of grouping students in different schools according to their ability. Woessmann et al. (2006) show that when grouping happens before age 10, inequality in education outcomes increases at the country level.

${ }^{7}$ James (1993) argues that the mix of public and private educational services is due, for example, to the degree of religious heterogeneity within a country.
} 
ers, ${ }^{8}$ then diversity is not a source of comparative advantage and there is no trade. Therefore their main result is that comparative advantage emerges only if there are two sectors, one supermodular and one submodular. ${ }^{9}$

Our modeling choices depart from GM's in two directions. First, we only consider supermodular production functions that simply vary in the degree of complementarity of workers' skills. This choice allows us to link our work more easily to the existing trade literature, in which most production functions are supermodular. The model features a continuum of sectors that vary in the elasticity of substitution across workers' skills. Second, we consider a world where, because of frictions in the labor market and unobservability of workers' skills, random matching prevails between workers and firms. ${ }^{10}$ This modeling choice is dictated primarily by tractability (our model can be easily applied to a world of many countries and many sectors), but it also reflects the fact that a large part of workers' skills is ex-ante unobservable to both workers and employers. ${ }^{11}$ Random matching implies that the skill distribution prevailing in a country is reflected at the firm and industry level. Recent international evidence (see Iranzo et al., 2008, and Lazear and Shaw, 2008) suggests that most of wage dispersion is in fact within, rather than between, firms.

We embed these features in a model of trade with monopolistic competition for two reasons. First, monopolistic competition smooths out the sharp trade predictions that would otherwise re-

\footnotetext{
${ }^{8}$ Supermodularity implies that the marginal product of a more able worker is increasing in the ability of the co-worker.

${ }^{9}$ Trade emerges only conditional on the existence of a supermodular sector, where workers of identical abilities are paired together, i.e. self-matching prevails, and of a submodular sector, where the most skilled workers are paired with the least skilled co-workers, i.e. cross-matching prevails. Submodularity of the production function implies that the marginal benefit of increasing a workers' skills is decreasing in the skills of the co-worker. In this framework the country with more dispersed skill distribution specializes in the submodular sector.

${ }^{10}$ We expand on an element introduced by GM, who consider imperfect observability of skills. At the end of the paper the authors "note in passing that, with imperfect matching, trade would take place between two countries with different educational processes even if tasks were complementary in all production activities", i.e. all production functions were super-modular, which is the case we consider. We extend this model to many countries and sectors in order to derive testable implications.

${ }^{11}$ In particular, as it will become clear in the empirical section, we refer to skills which are 'residual' and unrelated to observable characteristics of the workers.
} 
sult from a perfectly competitive Ricardian model. ${ }^{12}$ Moreover, similarly to Helpman and Itskhoki (2009a), Helpman et al.(2008a; 2008b), and for reasons discussed throughout the paper, we introduce simple labor market frictions, which are incompatible with perfect competition.

We show that, under some conditions, countries that have a more heterogeneous labor force export relatively more in sectors where the degree of complementarity among workers' skills is lower. Since the degree of complementarity across workers' abilities is not directly observable, we exploit the structure of the model, which delivers a direct link between the unobservable degree of complementarity and an observable quantity, namely the dispersion of sectoral wages. In our model, due to labor market frictions, workers hired by a firm are not interchangeable with workers outside such firm; therefore firms and workers engage in bargaining over the surplus. In the presence of random matching, the resulting wage distribution uniquely reflects the degree of complementarity among workers' skills. Sectors with higher complementarity are characterized by a more compressed wage distribution because, for example, workers with skills much higher than the average contribute to surplus relatively less, a fact reflected in their wage.

The second contribution of the paper is to test the prediction that countries with more dispersed skill distributions specialize, and therefore export relatively more, in sectors with higher wage dispersion. In order to bring the empirical analysis in line with the theoretical assumption of unobservable skills, we purge both our measure of skills (from the IALS) and individual workers' wages (from the US Census), of any component related to observable characteristics, to obtain residual scores and residual wages. We adapt the empirical approach of Helpman et al. (2008c), henceforth HMR, to industry-level trade flows and augment it with our variable of interest. We show that the interaction of country skill dispersion and sector wage dispersion is a significant and

\footnotetext{
${ }^{12}$ One of the points made by Costinot and Komunjer (2007) is that the sharp predictions of Ricardian models can be smoothed also by introducing random productivity differences across countries within each sector.
} 
economically large determinant of exports, even after controlling for a variety of trade barriers, exporting country and importing country-industry fixed effects (as dictated by the theory). We also include determinants of comparative advantage based on aggregate factor endowments as in Romalis (2004). Our empirical analysis provides robust evidence that skill dispersion matters as much as the aggregate endowment of skills in the determination of trade flows.

So far, we have extensively discussed the relation of this paper to its closest predecessor, GM. Three other papers present interesting alternative theoretical mechanisms for why the skill distribution matters for trade. Ohnsorge and Trefler (2007) propose a model with two-dimensional worker heterogeneity and show that, when each worker represents a bundle of two skills, the correlation of the two in the population determines comparative advantage. Grossman (2004) starts from the premise that, in some sectors, incomplete contracts make it difficult to tie remuneration to an individual worker's output. In a country with high skill dispersion highly skilled individuals prefer to sort into sectors where individual performance is easier to measure, rather than working in an industry where the common wage is dragged down by workers with relatively low skills. Grossman (2004) shows that this type of endogenous sorting determines comparative advantage. Finally, in Bougheas and Riezman (2007) comparative advantage emerges as a result of differential returns to skills in different sectors.

Our findings relate to recent literature emphasizing less traditional sources of comparative advantage. In this literature the endowment of a country, interpreted in its broadest sense, includes institutional features, such as the ability to enforce contracts (Levchenko, 2007, and Nunn, 2007), the quality of the financial system (Manova, 2008a; 2008b) and the extent of labor market frictions (Helpman and Itskhoki, 2009a, Cuñat and Melitz, 2007, Tang, 2008). We view our contribution as related to this 'institutional endowment' view of comparative advantage because human capital 
dispersion in a country is to a large extent the result of the prevailing educational system. This, in turn, can be considered, if not immutable, a slow-moving attribute of a country. ${ }^{13}$

Finally, as already mentioned, this paper also contributes to the large and established literature on factor endowments and comparative advantage, a topic which still receives a great deal of attention. For example, in a recent contribution to this literature, Costinot and Vogel (2009) build a model with a continuum of sectors and a continuum of skill levels and investigate the effect of trade on inequality in a rich framework. ${ }^{14}$

The paper is organized as follows. Section 2 develops the two-country multi-sector model and delivers the basic prediction about trade flows. Section 3 extends the model to many countries. Section 4 presents the empirical analysis. Section 5 concludes. All proofs and a detailed data description can be found in the Appendix.

\section{Two-Country Model}

This section presents a model of trade between two countries, Home and Foreign, characterized by different skill distributions. The two countries may also vary in size, but are otherwise identical. We denote a country by $c$ where $c \in\{H, F\}$. When it does not create ambiguity we drop the country subscript. Section 3 extends the model to a multi-country world.

\subsection{Preferences}

Each country $c$ is populated by a measure $L_{c}$ of individuals. Utility of the representative consumer depends on the consumption of a homogeneous good $Q(0)$ and a continuum of differentiated goods

\footnotetext{
${ }^{13}$ Glaeser et al. (2004) show that education is significantly more persistent than several other institutional features, such as the form of government.

${ }^{14}$ Besides their object of interest being different from this paper's, their assignment model yields the result that in equilibrium a sector employs only workers of a unique skill level, and as such it is not readily comparable to ours.
} 
$Q(i)$ with $i \in I$. The utility function $U$ is Cobb Douglas so that a constant share $\alpha(i)$ is spent on $\operatorname{good} i$ :

$$
\begin{aligned}
\log U & =\alpha(0) \log Q(0)+\int_{i \in I} \alpha(i) \log Q(i) d i \\
\text { with } 0 & <\alpha(i)<1 \text { and } \alpha(0)+\int_{i \in I} \alpha(i) d i=1
\end{aligned}
$$

where $Q(i)$ is the consumption index over the set $\Omega(i)$ of available varieties of product $i$. Preferences exhibit a constant elasticity of substitution $\sigma$ across varieties of good $i$ :

$$
Q(i)=\left[\int_{\omega \in \Omega(i)} q(\omega, i)^{\frac{\sigma-1}{\sigma}} d \omega\right]^{\frac{\sigma}{\sigma-1}} \text { with } \sigma>1
$$

where $q(\omega, i)$ is the quantity consumed of variety $\omega$ of good $i$. Under these preferences, demand for a given variety $\omega$ is represented by the following equation:

$$
d(\omega, i)=\frac{p(\omega, i)^{-\sigma} \alpha(i) E}{P(i)^{1-\sigma}}
$$

where $E$ is total expenditure, $p(\omega, i)$ is the price of variety $\omega$ of $i$, and $P(i)$ is the ideal CES price index of aggregate $Q(i)$.

\subsection{Production}

Good $Q(0)$ is produced under constant returns to scale by perfectly competitive firms. The technology is such that one unit of labor produces one unit of output. We choose $Q(0)$ as our numeraire and we assume that all countries produce the numeraire good in positive quantity, which implies that the wage in sector $0, w(0)$, is equal to one.

Each differentiated sector $i$ is populated by a continuum of identical firms, each producing a 
different variety $\omega$. The market is characterized by monopolistic competition among firms, with free entry. There is also a fixed cost of production $f$. The amount of output produced $y$ depends on the skill level of each worker hired $a$, the measure of workers hired $h$ and the distribution of skills across workers $\tilde{g}(a)$. The distribution of skills matters for production because we assume that different levels of skills are not perfectly substitutable. ${ }^{15}$ In particular, the production function of a representative firm in a sector depends on the degree of complementarity $\lambda$ among workers' skills in that sector and takes the following form:

$$
y=\left(\int a^{\lambda} h \tilde{g}(a) d a\right)^{\frac{1}{\lambda}} \text { with } \frac{\sigma-1}{\sigma}<\lambda<1
$$

The parameter $\lambda$ measures the degree of skill complementarity, since the elasticity of substitution among skills levels, for a fixed mass of workers $h$, is given by $\frac{1}{1-\lambda}$, which increases with $\lambda$. The larger $\lambda$, the more substitutable workers of different skill levels are. ${ }^{16}$ The key assumption in this model is that each sector $i$ is characterized by a different value of $\lambda$ in production, and therefore by a different degree of complementarity among workers' skill levels. Since $\lambda$ is the only characteristic that differentiates sectors, in the remainder of the theoretical section we drop the index $i$ and index sectors by their parameter $\lambda$.

Two properties of this production function are worth discussing in detail. First, for given mass of workers $h$, the function is homogeneous of degree one in the skills of workers. This property stresses the relative importance of the shape, rather than location, of the distribution of skills. Second, the production function features increasing returns to the mass of workers, given the distribution

\footnotetext{
${ }^{15}$ One possible interpretation is that the skill of each worker is a differentiated input in the production process. An alternative interpretation, along the lines of the paper by Takii and Tanaka (2009), is that each worker produces a differentiated intermediate good, in quantity proportional to her skills, and intermediate inputs are aggregated by a CES production function.

${ }^{16}$ For a fixed $h$, this production function is analogous to the one introduced by Grossman and Maggi (2000), p. 1261.
} 
of skills. ${ }^{17}$ In particular, $\lambda$ also represents the extent of increasing returns to scale (as well as the degree of complementarity), but this feature plays no important role in the model. ${ }^{18}$ We restrict the size of $\lambda$ to guarantee that the firm's maximization problem is concave, as described in Section 2.5 .

\subsection{Labor Market}

We introduce labor market frictions in the spirit of Helpman and Itskhoki (2009a), although for simplicity we assume that there are no frictions in sector 0 . Workers look for jobs in the homogeneous sector or in one of the differentiated good sectors. Workers are characterized by different levels of skills and skill is a continuous variable distributed in the workers' population of country $c$ according to a density function $g(a, c)$. In the differentiated sectors firms pay a cost $b h$ to randomly sample a mass $h$ of workers from the population of workers looking for a job in that sector. The search cost $b$ depends on the labor market conditions, as described further below.

We follow Helpman and Itskhoki (2009a) and Helpman et al. (2008a) in making the simplifying assumption that workers do not know their own skills when looking for a job. As a result the initial distribution of skills in the worker population will be inherited by the mass of workers looking for a job in each sector. ${ }^{19}$ We also assume that worker's skills are not observable to the firm when hiring. The combination of these assumptions yields no sorting between workers and firms. Although analytically convenient, these assumptions certainly deserve a discussion. We offer two

\footnotetext{
${ }^{17}$ This is easily seen by rewriting the production function as $y=h^{\frac{1}{\lambda}}\left(\int a^{\lambda} \tilde{g}(a) d a\right)^{\frac{1}{\lambda}}$.

${ }^{18}$ We should note that it is not possible to obtain both constant returns to mass of workers and ability without confounding the quantity and quality of workers, as for example in a production function of the following type: $y=\left(\int(a h \tilde{g}(a))^{\lambda} d a\right)^{\frac{1}{\lambda}}$. We give priority to maintaining constant returns to ability because we do not want to confound the degree of complementarity with differential returns to aggregate ability in different sectors. Grossman and Maggi (2000) discuss this as another case in which the distribution of ability matters and Bougheas and Riezman (2007) explicitly model this aspect in a different framework.

${ }^{19} \mathrm{An}$ alternative interpretation is that workers are aware of their own ability, but are ex-ante ignorant about the distribution of wages in all sectors (including the numeraire), except for the expected wage and the probability of unemployment.
} 
ways of interpreting random matching. First, it might be the case that productivity in a specific job mainly depends on the firm-worker match and this might be unknown to the worker and to the firm until production takes place. Second, skills might be partially observable by both firms and workers, which corresponds to the case analyzed by GM. They have shown that if skills are fully observable and production functions are supermodular, workers of identical skills are matched together, and countries with different skill distributions do not trade. If we allowed skills to be partially observable in our model we would obtain that firms only hire workers of identical observable skills. Therefore we can interpret our case of unobservable skills as a residual of overall skills, when we take out the observable component. For consistency with this, the empirical analysis will employ a measure of skills purged of all observables.

Although the distribution of workers' skills $\tilde{g}(a)$ could potentially be sector specific, random matching implies that every firm, in every sector $\lambda$, in country $c$ inherits the skill distribution in the general population: ${ }^{20}$

$$
\tilde{g}(a)=g(a, c)
$$

\subsection{Skill Dispersion as Comparative Advantage}

Given that firms and workers match randomly with respect to unobservable skills, in this section we discuss how different skill distributions across countries generate comparative advantage in this world. To facilitate the discussion we rewrite the production function in $(2)$ as $y=h^{\frac{1}{\lambda}} A(\lambda, c)$ where $A(\lambda, c)$ is defined as:

$$
A(\lambda, c)=\left(\int a^{\lambda} g(a, c) d a\right)^{\frac{1}{\lambda}}
$$

\footnotetext{
${ }^{20}$ We do not allow firms to screen workers as in Helpman et al. (2008a). We note that, contrary to the case described by Helpman et al. (2008a), with our choice of production function, firms would not want to screen workers even if the technology to screen were available, because the marginal product of an additional worker is always positive. This is the case because of the static problem we are analyzing. In a dynamic framework we would expect firms to lay off unproductive workers and replace them with potentially more productive ones.
} 
We loosely refer to $A(\lambda, c)$ as 'productivity', although clearly this is not the result of countries having access to different technologies. The magnitude of $A(\lambda, c)$ depends on a combination of a country-specific skill distribution and a sector-specific level of complementarity across skills. We are interested in how the pattern of comparative advantage, i.e. the relative $A$ 's, are affected by the distribution of skills.

The general idea we explore is whether countries with lower dispersion in the distribution of skills have a comparative advantage in sectors with high degree of complementarity, i.e. where it is relatively more important to employ workers with similar skills. Since the $A$ 's exhibit constant returns to skills, a proportional increase in the skills of all workers increases the $A$ by the same proportion and does not affect comparative advantage. Therefore we concentrate on comparing $A$ 's across countries that have the same average skills and different dispersion. ${ }^{21}$ We first state a general condition for a specific pattern of comparative advantage to emerge as a result of differences in the distribution of skills.

Property 1 If countries are ordered so that, if $c<c^{\prime}$, then country $c^{\prime}$ is characterized by a skill distribution $g\left(a, c^{\prime}\right)$ that is a mean-preserving spread of the skill distribution $g(a, c)$ in country $c$, then $A(\lambda, c)$ is log-supermodular in $\lambda$ and $c$, i.e. for $\lambda<\lambda^{\prime}$ and $c<c^{\prime}$ :

$$
\frac{A\left(\lambda, c^{\prime}\right)}{A(\lambda, c)}<\frac{A\left(\lambda^{\prime}, c^{\prime}\right)}{A\left(\lambda^{\prime}, c\right)}
$$

Having stated the general property that we are interested in, we now study under which conditions Property 1 holds. As GM suggest, ${ }^{22}$ a general result of this type cannot be established. Because our ultimate goal is to derive empirical implications, we take three different approaches

\footnotetext{
${ }^{21}$ Note that changes in the average ability that are not the result of a multiplicative change in all abilities will affect the pattern of comparative advantage.

${ }^{22}$ See p. 1271.
} 
to studying this problem. First, we show that comparative advantage can be established for any distribution if we place bounds on the degree of complementarity $\lambda$. Second, we perform comparative statics assuming specific distributions of skills. Third, we construct $A(\lambda, c)$ using the empirical distribution of IALS scores, our proxy for skills.

Our first approach yields a general result based on restrictions on the degree of complementarity and on the upper bound of the support of the skill distribution. ${ }^{23}$

Proposition 1 Property 1 holds, i.e. a country $c^{\prime}$ with a more dispersed skill distribution than country c has a comparative advantage in sectors with lower complementarity (higher $\lambda$ ) under the following sufficient conditions:

(i) Skill is bounded from above by $a_{\max }$

(ii) The degree of complementarity is low enough: $\lambda>\bar{\lambda}$ where $\bar{\lambda}$ is defined by the following condition

$$
\log a_{\max }=\frac{2 \bar{\lambda}-1}{(1-\bar{\lambda}) \bar{\lambda}}
$$

In our second approach to studying Property 1 we relax the conditions on complementarity at the cost of concentrating on specific distributions. We can only consider continuous distributions that are characterized by at least two parameters (in order to be able to consider mean-preserving increases in dispersion) and are defined on a positive support.

Proposition 2 If skills are distributed according to a Pareto or Log-normal distribution then, if country $c$ and $c^{\prime}$ are characterized by skill distributions $g(a, c)$ and $g\left(a, c^{\prime}\right)$ such that $g\left(a, c^{\prime}\right)$ has equal mean and higher variance than $g(a, c)$ and if $\lambda<\lambda^{\prime}$ then Property 1 holds, i.e. country $c^{\prime}$ has a comparative advantage in $\lambda^{\prime}$.

\footnotetext{
${ }^{23}$ Imposing an upper bound on $a$ is realistic because it means we do not admit the existence of infinitely productive workers.
} 
While Proposition 2 establishes an analytical result, we have also numerically computed the A's for the following distributions: uniform, triangular, gamma, beta and inverse gaussian. For all these distributions, and for a wide range of parameters, we cannot find a violation of the ranking in $(3) \cdot{ }^{24}$

In our third approach we compute the $A$ 's for different countries and sectors employing the empirical distributions of IALS log-scores. We verify that Property 1 holds. For a grid of $100 \lambda$ 's in the $[0,1]$ interval, we calculate the ratio of $\frac{A\left(\lambda, c^{\prime}\right)}{A(\lambda, c)}$ where $c^{\prime}$ has higher skill dispersion than country $c$ according to the coefficient of variation of scores. We then regress this ratio on $\lambda$ and find that, in 169 out of 171 possible pairs of countries, the gradient is positive and strongly significant, in agreement with equation (3). ${ }^{25}$

\subsection{The Firm Problem and Bargaining}

This section analyzes the problem of a representative Home firm in a given sector. Analogous expressions can be derived for a Foreign firm. Firms can sell in the domestic market or export, facing a transport cost. The transport $\operatorname{cost} \tau$ is of the iceberg type, so that firms have to ship $\tau>1$ units of good in order for one unit to arrive. We denote by $x_{c c^{\prime}}$ a variable $x$ originating in market $c$ and destined for market $c^{\prime}$. We drop the sector index to simplify notation.

A Home firm must decide how much to produce for the Home and Foreign market and, since it maximizes profits, it equates marginal revenues across the two markets. This allows us to write

\footnotetext{
${ }^{24} \mathrm{~A}$ violation of the ranking can be engineered using a result by Ross (1981). The intuition is the following. Ross (1981) shows that, if we adopt the Arrow-Debreu definition of risk aversion, then, starting from a given lottery, we might find the counterintuitive result that a more risk-averse individual is willing to pay less than a less risk-averse individual to avoid an an increase in risk in the sense of a mean-preserving spread. We can view our $A$ as the certainty equivalent of lottery $g$ for an individual with Bernoulli utility $u(a)=a^{\lambda}, 0<\lambda<1$. Individuals with lower $\lambda$ are more risk averse in the Arrow-Pratt sense. In our case we can show, using the example proposed by Ross (1981) that, with a mean-preserving spread, the certainty equivalent of a more risk averse individual drops proportionately by less than for a less risk averse individual. Details are available from the authors.

${ }^{25}$ Numerical results and details of all these exercises are available from the authors.
} 
total revenues of a Home firm $r_{H}$ as a function of total output:

$$
r_{H}=y_{H}^{\frac{\sigma-1}{\sigma}} \Gamma_{H}
$$

where $y_{H}=y_{H H}+y_{H F}, \Gamma_{H}=\left(B_{H}^{\sigma}+B_{F}^{\sigma} \tau^{1-\sigma}\right)^{\frac{1}{\sigma}}$ and $B_{c}=P_{c} Q_{c}^{\frac{1}{\sigma}}$ for $c=H, F .{ }^{26}$ The firm must then simply choose the total amount of output to produce and therefore how many workers to employ. In this decision it takes into account how much workers are paid.

Because of the presence of search frictions, once workers are hired they are not interchangeable with outside workers and we assume that the firm and all workers employed engage in bargaining to share the surplus created. We assume that the intra-firm bargaining is of the type described by Stole and Zwiebel (1996), with the workers having unemployment as outside option, which we assume yields a payoff of zero. Stole and Zwiebel show that the bargaining solution yields payoffs that correspond to the Shapley value. We discuss wages in the following section, while here we show that the bargaining outcome for a firm with revenues $r$ is given by $s r$, where:

$$
s=\frac{\sigma \lambda}{\sigma(1+\lambda)-1}
$$

Given the expression for total revenues in (4), the firm static problem ${ }^{27}$ reduces to choosing how many workers to hire $(h)$ to maximize profits $\pi$ :

$$
\max _{h} \pi=s\left[A(\lambda, H) h^{\frac{1}{\lambda}}\right]^{\frac{\sigma-1}{\sigma}} \Gamma_{H}-b h-f
$$

\footnotetext{
${ }^{26}$ Total revenues are given by $r_{H}=B_{H} y_{H H}^{\frac{\sigma-1}{\sigma}}+B_{F} y_{H F}^{\frac{\sigma-1}{\sigma}} \tau^{\frac{1-\sigma}{\sigma}}$. The equality of marginal revenues across markets, which implies $\frac{y_{H H}}{y_{H F}}=\left(\frac{B_{H}}{B_{F}}\right)^{\sigma} \tau^{\sigma-1}$ and some algebraic manipulation lead to (4), similarly to Helpman and Itskhoki (2009a).

${ }^{27}$ For a dynamic extension of this type of framework see Helpman and Itskhoki (2009b).
} 
This is a concave problem because of the restriction placed on $\lambda$ in (2). Since this is a standard problem we refer to the Appendix for details of the derivation, and report here the main results. The total output produced by a Home firm is given by:

$$
y_{H}=A(\lambda, H) \phi
$$

where $\phi(\lambda)=\left[\frac{f(\sigma-1)}{b(1+(\lambda-1) \sigma)}\right]^{\frac{1}{\lambda}}$. Intuitively, output is increasing in productivity $A$, the size of the fixed cost $f$, and the elasticity of demand $\sigma$, while it decreases with the hiring cost $b{ }^{28}$ We assume that differences in productivity between Home and Foreign firms in a given sector are not too large, that is:

$$
\frac{1}{\tau} \leq \frac{A(\lambda, H)}{A(\lambda, F)} \leq \tau \quad \forall \lambda
$$

otherwise the amount produced is zero. Under condition (7) we can derive how much output is produced for the domestic and export market, $y_{H H}$ and $y_{H F}$ respectively (see Appendix). As standard with iso-elastic demand, the producer price is constant across markets and for a Home firm is equal to $p_{H}=\frac{\gamma}{\phi A_{H}}$ where $\gamma(\lambda)=f \frac{\sigma \lambda+\sigma-1}{\sigma \lambda-\sigma+1}$. The consumer price in the export market is the producer price multiplied by $\tau$ :

$$
p_{H F}=\frac{\gamma \tau}{\phi A_{H}}
$$

In the Appendix we derive revenues accruing to firms in all markets. We focus attention here on the relative revenues (i.e. value of output sold) of a Home and Foreign firm in a given market, for example Foreign:

$$
\frac{r_{H F}}{r_{F F}}=\left(\frac{A(\lambda, H)}{\tau A(\lambda, F)}\right)^{\sigma-1}
$$

\footnotetext{
${ }^{28}$ The hiring cost depends on tightness of the labor market $x$, and is assumed to take the same form as in Helpman and Itskhoki (2009a) and Helpman et al. (2008a): $b=\delta_{0} x^{\delta_{1}}$. We refer to these papers for a discussion. We similarly obtain that in equilibrium the hiring cost is constant across sectors, i.e. $b=\delta_{0}^{\frac{1}{1+\delta_{1}}}$.
} 
Intuitively, relative revenues increase in relative productivity, as predicted by comparative advantage. In the next section we solve for the mass of firms, which is the final step in the determination of trade flows.

\subsection{Trade Flows}

In Section 2.5 we derived the amount of output sold by each firm in the domestic and export market. In order to determine trade flows we need to calculate the equilibrium mass of firms for country $c$ and sector $\lambda, M_{c}(\lambda)$. The derivation is presented in the Appendix. We remark that, similarly to other models of monopolistic competition with trade costs (Helpman and Krugman, 1985), the presence of a home-market effect requires that we restrict the degree of asymmetry in country sizes to prevent all firms from locating in one country. Define relative population in Home as $\eta \equiv \frac{L_{H}}{L_{F}}$. We impose throughout the restrictions that $\eta_{l o w}<\eta<\eta_{u p}$. If the condition is violated for some industries, we expect to observe no production and no exports. ${ }^{29}$ If the condition is satisfied, then the following proposition establishes a link between comparative advantage and equilibrium entry.

Proposition 3 Under the condition that country sizes are sufficiently similar, i.e. $\eta_{\text {low }}<\eta<\eta_{\text {up }}$, the equilibrium mass of firms in country $H$ relative to country $F$ in sector $\lambda^{\prime}$ is higher than in sector $\lambda$ if and only if country $H$ has a comparative advantage in sector $\lambda^{\prime}$, i.e.

$$
\frac{A(\lambda, H)}{A(\lambda, F)}<\frac{A\left(\lambda^{\prime}, H\right)}{A\left(\lambda^{\prime}, F\right)} \Longleftrightarrow \frac{M_{H}(\lambda)}{M_{F}(\lambda)}<\frac{M_{H}\left(\lambda^{\prime}\right)}{M_{F}\left(\lambda^{\prime}\right)}
$$

\footnotetext{
${ }^{29}$ As equations (A-19) and (A-20) establish, the conditions for a positive mass of firms depend on size, but also on comparative advantage. If a country is relatively more productive it can afford to be smaller in size and still have a positive mass of firms. In this sense our model also predicts an extensive margin of trade (whether we observe or not trade between two countries) based on comparative advantage, albeit a very stark one. Differently from models with heterogeneous firms, e.g. Helpman et al. (2008c), in this setup the assumption of identical firms implies that either firms exist and export or they do neither.
} 
Since trade flows are completely determined by the amount sold in the export market by each firm and by the number of firms, we now show that the value of exports is relatively higher in comparative advantage industries. In the previous section we have established that comparative advantage is determined by a combination of sector characteristics (the degree of complementarity $\lambda)$ and country characteristics (the dispersion of skills in the population). The following proposition summarizes the previous discussion and represents the main result of this section. We denote the value of total sales by firms from country $c$ in market $c^{\prime}$, as $X_{c c^{\prime}}$. Relative total sales of good $\lambda$ by Home and Foreign firms in a given market, for example Foreign, are then equal to:

$$
\frac{X_{H F}(\lambda)}{X_{F F}(\lambda)}=\frac{r_{H F}(\lambda) M_{H}(\lambda)}{r_{F F}(\lambda) M_{F}(\lambda)}
$$

Proposition 4 Under Property 1, a country with relatively higher dispersion of skills has a comparative advantage, and therefore exports relatively more to any destination, in sectors with high degree of substitutability $\lambda$.

The next section provides a bridge to the empirical section by extending the model to a multicountry world.

\section{Multi-Country Model}

The goal of this section is to generalize the model to many countries and provide the conditions under which the main result of the two-country model holds, i.e. countries with relatively higher dispersion of skills have a comparative advantage, and therefore export relatively more, in sectors where the dispersion of wages is higher.

Without loss of generality we consider three countries, so that $c \in\{H, F, G\}$. Following HMR, 
we allow transport costs to be country-pair specific and asymmetric, i.e. $\tau_{H F} \neq \tau_{F H}$. We fix as destination market country $F$ and express the value of exports of good $\lambda$ by country $H$ relative to country $G$ as follows:

$$
\frac{X_{H F}(\lambda)}{X_{G F}(\lambda)}=\frac{r_{H F}(\lambda) M_{H}(\lambda)}{r_{G F}(\lambda) M_{G}(\lambda)}
$$

While the determination of relative revenues of individual firms $r_{H F} / r_{G F}$ is straightforward, the equilibrium mass of firms can be computed, but not easily characterized, with more than two asymmetric countries. This is a known problem in the home-market effect literature. ${ }^{30}$ Therefore in the following proposition we limit ourselves to imposing that the relative mass of firms be nondecreasing in relative productivity. This is reasonable if we believe that, in equilibrium, entry is relatively higher in sectors where a country has a comparative advantage.

Proposition 5 Under Property 1, if the relative mass of firms $\frac{M_{H}(\lambda)}{M_{G}(\lambda)}$ is non-decreasing in relative productivity $\frac{A(\lambda, H)}{A(\lambda, G)}$ then a country with relatively higher dispersion of skills has a comparative advantage, and therefore exports relatively more to any destination, in sectors with higher degree of substitutability $\lambda$.

\subsection{Wage Distribution and Complementarity}

The previous sections establish the direction and magnitude of trade flows based on comparative advantage, which results from a combination of sector characteristics (the parameter $\lambda$ ) and country characteristics (skill dispersion). While we have measures that approximate the degree of skill dispersion at the country level, we are not aware of any measures of the elasticity of substitution among individuals' skills in different sectors. Therefore we take the theoretical model as a guide

\footnotetext{
${ }^{30}$ Behrens et al. (2009) show that the home-market effect intuition does not easily generalize to the case of more than two countries. Our case of multiple countries with productivity differences further complicates the problem and is beyond the scope of this paper.
} 
to finding a proxy for the degree of complementarity. This section establishes a one-to-one link between the degree of complementarity and the dispersion of wages in sector $\lambda$, which can be measured in the data.

We assume that at the bargaining and production stage workers' skills are fully revealed, so that workers of different skills receive different wages as a result of intra-firm bargaining. Although the assumption that skill is perfectly revealed only at the production and bargaining stage is stark, we believe it captures some realistic features of the hiring process, where workers' skills in particular tasks are difficult to assess until they start working. Moreover, even if skills were partially revealed at the production stage, as long as the portion revealed were constant across sectors, this would not substantially change the implications we are about to discuss.

The Appendix shows the calculation of the Shapley value for a worker of skill $a$. Since the average wage also differs across sectors, we normalize the wage of a worker of skill $a$ in sector $\lambda$ by the average wage in the sector. The normalized wage is $\widetilde{w}(a, \lambda)=\frac{a^{\lambda}}{E\left(a^{\lambda}\right)}$, which reflects the marginal product of a worker of skill $a$ when added to the production team and depends on $\lambda$. The higher the substitutability across workers the larger the marginal product of a worker with high skills. In contrast, if $\lambda$ is low, i.e. complementarity is high, a worker of high skills has a relatively lower marginal product because her skills are very different from the average skills of her team-mates. An implication of this wage structure is that workers with identical skills, but employed in different sectors, generally receive different wages, as returns to skills vary across industries. ${ }^{31}$

Keeping in mind that the distribution of skills is the same in every industry, the distribution of wages within a sector depends, in our framework, exclusively on technological factors that determine the marginal product of workers with different skills. It therefore does not reflect compo-

\footnotetext{
${ }^{31}$ The point is made by Heckman and Scheinkman (1987), who show that returns to unobservable characteristics are different across sectors.
} 
sitional differences across sectors. The following proposition establishes that there is a one-to-one correspondence between the dispersion of wages and the degree of complementarity.

Proposition 6 For any non-degenerate distribution of skills $g(a, c)$, the following three measures of dispersion of sectoral wages are strictly increasing in the degree of substitutability of workers' skills, $\lambda$ : (i) the Coefficient of Variation; (ii) the Gini Coefficient and (iii) the Inter-Percentile $\operatorname{Ratio}^{32}$

Proposition 6 establishes that the more complementary workers are, the more compressed the wage distribution is. The intuition follows from our discussion of normalized wages.

\section{Empirical Analysis}

Section 3 extended the two-country model to the case of many countries. The objective of this section is to assess the empirical relevance of Proposition 5. A difficulty comes from the fact that the elasticity of substitution of individuals' skills at the industry level is not observable in the data. However, combining results from Propositions 5 and 6 , it is possible to derive the following testable implication of our model:

Corollary 7 Under Property 1, if the relative mass of firms is non-decreasing in relative productivity, then a country with a relatively higher skill dispersion has a comparative advantage, and therefore exports relatively more to any destination, in sectors where the dispersion of wages is higher.

Proof. Follows immediately from Propositions 5 and 6.

\footnotetext{
${ }^{32}$ The Interpercentile-Ratio, $I P R_{k j}$, is defined as $I P R_{k j}=\frac{w_{k}}{w_{j}}$, where $w_{k}\left(w_{j}\right)$ is the wage of the worker at the $k^{t h}\left(j^{t h}\right)$ percentile of the sectoral wage distribution and $j<k$.
} 
Next we present the estimation framework. Section 4.2 describes the data and section 4.3 reports baseline results. Finally, Section 4.4 discusses identification and presents robustness checks.

\subsection{Estimation Framework}

As a first step to design an empirical test of Corollary 7 we combine equations (1) and (8) to obtain the following expression for the value of (log) exports of good $i$ from country $H$ to country $F$, $X_{H F}(i):{ }^{33}$

$$
\begin{aligned}
\log X_{H F}(i)= & (\sigma-1) \log A(i, H)+\log M_{H}(i)-(\sigma-1) \log \tau_{H F} \\
& +\log \alpha(i)+\log E_{F}-(\sigma-1) P_{F}(i)+(\sigma-1) \log \frac{\phi(i)}{\gamma(i)}
\end{aligned}
$$

where $A(i, H)$ captures comparative advantage of the exporting country, $M_{H}(i)$ the mass of firms in the exporting country, $\tau_{H F}$ transport costs between the two countries, $P_{F}(i)$ an industry-importer specific price index, $E_{F}$ the importing country total expenditure and $\phi(i), \gamma(i)$ and $\alpha(i)$ industryspecific constants. Since we analyze a discrete number of industries, in the remainder of this section we use subscript $i$ to index variables that vary across industries.

An ideal test of Corollary 7 would require quantifying the effect of a mean-preserving spread in the distribution of skills in country $H$ on its relative exports to country $F$, as a function of the elasticity of substitution in each sector $i$. These effects operate through $A_{H i}$ in equation 11. Although $M_{H i}$ is not observable, the model shows it is also a function of $A_{H i}$. Therefore, in order to derive an estimation equation for $\log X_{H F i}$, we assume that $(\sigma-1) \log A_{H i}+\log M_{H i}$ can be

\footnotetext{
${ }^{33}$ The value of total exports of $i$ from $H$ to $F$ is given by:

$$
X_{H F}(i)=d_{H F}(i) p_{H F}(i) M_{H}(i)=\frac{\left[p_{H F}(i)\right]^{1-\sigma} \alpha(i) E_{F}}{\left[P_{F}(i)\right]^{1-\sigma}} M_{H}(i)
$$

where $p_{H F}(i)=\frac{\gamma(i) \tau_{H F}}{\phi(i) A(i, H)}$.
} 
written as an additive function of industry characteristics $\left(\delta_{i}\right)$, exporter characteristics $\left(\delta_{H}\right)$, an interaction between a measure of wage dispersion in industry $i$ (WageDisp ${ }_{i}$ ) and a measure of skill dispersion in country $H\left(S k i l l D i s p_{H}\right)$, and other unobservable determinants of comparative advantage in country $H\left(\nu_{H i}\right),{ }^{34}$

$$
(\sigma-1) \log A_{H i}+\log M_{H i}=\beta W a g e \text { Disp }_{i} \times \text { SkillDisp }_{H}+\delta_{i}+\delta_{H}+\nu_{H i}
$$

Transport costs are allowed to depend linearly on a vector of observable country-pair bilateral trade barriers $\left(d_{H F}\right)$ and unmeasured i.i.d. trade frictions $\left(u_{H F}\right)$. A set of industry-importer specific fixed effects $\left(\delta_{F i}\right)$ controls non-parametrically for the price index $P_{F i}$, industry constants $\frac{\phi_{i}}{\gamma_{i}}$ and $\delta_{i}$. Finally, let $\eta_{H F i}$ capture measurement errors in trade flows and the effect of other unobserved determinants of $X_{H F i}$.

With this specification, the estimation equation for exports $\log X_{H F i}$ takes the following form:

$$
\log X_{H F i}=\beta W \text { ageDisp }_{i} \times \text { SkillDisp }_{H}+\gamma d_{H F}+\delta_{H}+\delta_{F i}+\varepsilon_{H F i}
$$

where $\varepsilon_{H F i}=\nu_{H i}+u_{H F}+\eta_{H F i}$.

The variable of interest is $W a g e D i s p_{i} \times S k i l l D i s p_{H}$ and estimation of its coefficient $\beta$ allows us to test Corollary 7. To see why, assume that equation (12) correctly specifies a model for the conditional expectation of $\log X_{H F i}$, so that $E\left[\varepsilon_{H F i} \mid\right.$ WageDisp $\left.i \times S k i l l D i s p_{H}, d_{H F}, \delta_{H}, \delta_{F i}\right]=0$. Then, for any two countries $H$ and $G$ exporting to $F$, and any two industries $i$ and $j$, equation (12) implies:

$$
E\left[\log \left(\frac{X_{H F i}}{X_{G F i}}\right)-\log \left(\frac{X_{H F j}}{X_{G F j}}\right)\right]=\beta \Delta_{i j} \text { WageDisp } \times \Delta_{H G} \text { SkillDisp }
$$

\footnotetext{
${ }^{34}$ Note that $A_{H i}$ may also depend on the mean and other moments of the skill distribution of country $H$ and these could potentially have different effect on productivity in different industries, a possibility that we explicitly consider in the empirical analysis of trade flows. These effects are summarized by $\nu_{H i}$.
} 
where $\Delta_{H G}$ SkillDisp $\equiv$ SkillDisp $p_{H}-$ SkillDisp $p_{G}$ and $\Delta_{i j}$ WageDisp is similarly defined. According to (13), Corollary 7 implies $\beta>0$.

\subsection{Data}

Before presenting the estimation results we briefly describe the measurement of the two key explanatory variables in the empirical analysis, skill dispersion at the country level and wage dispersion at the industry level. A detailed discussion of all data can be found in the Appendix.

\subsubsection{Skill Dispersion}

We use test scores from the International Adult Literacy Survey (IALS) to approximate the skill distribution within a country. Collaborators in this household survey administered a common test of work-related literacy skills to a large sample of adults between the ages of 16 and 65 in 19 countries. The IALS focuses on literacy skills that are needed for everyday tasks (e.g. working out a tip, calculating interest on a loan and extracting information), across three different dimensions of literacy: quantitative, prose and document literacy. We combine the results of these three tests into a single average score for each individual, measured on a scale from 0 to 500. The skill distribution is proxied by the distribution of log-scores of individuals participating in the labor market and living in the same country.

To insure consistency with the theoretical assumption of imperfect skill observability, we construct a measure of residual scores dispersion within countries. For an individual $k$ participating in the labor market of country $H$, we obtain the estimated residual $\widehat{\epsilon_{k H}}$ from the following regression:

$$
\log \left(s_{k H}\right)=X_{k H} \beta_{H}+\epsilon_{k H}
$$


where $s_{k H}$ is the IALS score of $k$ and $X_{k H}$ is a vector of individual demographic information from the IALS questionnaire. The residual $\widehat{\epsilon_{k H}}$ is then used to compute the skill dispersion measures used for the estimation of trade flows.

Table 1 ranks 19 countries according to the coefficient of variation (CV) of IALS scores, and also reports their rank by mean, standard deviation (St Dev) and standard deviation of residual IALS (St Dev Resid). The figures show different dispersion in countries at similar stages of development: for example, we observe a more spread distribution of skills in the US, UK and Canada, than in Sweden, the Netherlands and Germany. ${ }^{35}$

\subsubsection{Wage Dispersion}

We use the 5\% Public Use Microdata Sample (PUMS) files of the 2000 Census of Population in the United States to construct industry-specific measures of wage dispersion to be used as proxies for the unobserved elasticity of substitution. An advantage of our approach is that we can match individual wage observations to a detailed industry classification, accounting for the entire manufacturing sector ${ }^{36}$. As shown in table 2, this procedure results in 63 industries for which both wage dispersion and international trade flows can be computed, at a level of aggregation between the 3 and 4 digit levels of the 1997 North American Industry Classification System (NAICS).

As with IALS scores, we focus on residual wage dispersion. We start by removing variation in wages driven by a set of individual characteristics on which firms can typically condition employment decisions. Then, we adapt the correction method proposed in Dahl (2002) to address the possibly non-random selection of workers into multiple industries. In essence, this procedure controls for

\footnotetext{
${ }^{35}$ Brown et al. (2007) report similar variation in skill distributions in a comprehensive study using IALS, the 1995, 1999 and 2003 Trends in International Maths and Science Study (TIMSS), the 2000 and 2003 Programme for International Student Assessment (PISA) and the 2001 Progress in International Reading Literacy Study (PIRLS).

${ }^{36}$ This is not feasible for IALS data, since individual observations are assigned a broad sectoral classification (e.g. agriculture, mining, manufacturing, construction, etc), while international trade data is available only for manufacturing industries.
} 
selection effects using differences in the probabilities of being observed in a given industry due to exogenous variation, such as the state of birth of two people, who are otherwise similar in terms of education, experience, household structure, race and gender. Details are provided in the Appendix.

For an individual $k$ employed in industry $i$, we obtain the estimated residual $\widehat{\xi_{k i}}$ from the following regression:

$$
\log \left(w_{k i}\right)=Z_{k i} \beta_{i}+\xi_{k i}
$$

where $w_{k i}$ is the weekly wage of $k$ and $Z_{k i}$ is a vector of observable characteristics. Note that we run these regressions separately for each industry to allow for changes in the return to observable characteristics across industries. ${ }^{37}$ Table 2 shows the ranking of different industries by standard deviation of raw and residual wages. It is apparent that dispersion varies significantly across sectors. For example, in terms of the standard deviation of wages, the three lowest ranked sectors are non-ferrous metal processing, railroad, and fiber mills. The three highest ranked are cosmetics, computer and electronic manufacturing.

The use of U.S. estimates as proxies for within-industry wage dispersion (and skill substitutability) in other countries is warranted if they have access to similar production technologies. ${ }^{38}$ Equal access to technology implies that the elasticity of substitution in any given industry will be constant across countries. As a result, the ranking of industries according to wage dispersion will be the same within each country, a hypothesis that is not easy to verify due to the scarcity of publicly available microdata with similar sector classification. However, we do perform this exercise for the U.S. and Canada. We compute the sectoral dispersion of wage residuals in Canada to verify

\footnotetext{
${ }^{37}$ Regression results are available upon request.

${ }^{38}$ The assumption that industry-specific characteristics computed for the United States also apply to industries in other countries is not an unusual one in the recent empirical trade literature on comparative advantage. Examples include the measurement of financial vulnerability (Manova, 2008b), the importance of relationship-specific investment (Nunn, 2007), firm-specific skill intensity (Tang, 2008) and the variance of firm-specific shocks (Cuñat and Melitz, 2007).
} 
whether the ranking is similar to the one prevailing in the US. ${ }^{39}$ To maximize comparability, we are careful to control for the same set of observable characteristics of workers in both countries when computing the residuals, use similar sampling criteria and the same industry classification. Figure 2 shows the standard deviation of the wage residuals in the two countries by industry. The positive slope of the fitted line is significant at the $5 \%$ level. Clearly, the sectoral ranking of residual dispersion in the US is strongly correlated to the one observed in Canada. Sectors like computers and clothing exhibit higher dispersion in both countries, compared to sectors like machinery and paper manufacturing.

\subsection{Baseline Results}

This section discusses results of the empirical analysis of trade flows using specification (12). The dependent variable in tables 3 to 5 is the log of exports from country $H$ to country $F$ in industry i. Our data set contains the value of exports in year 2000 from 19 exporters to 145 importers in 63 industries. Table 3 reports estimates of the impact of skill dispersion as proxied by the dispersion of (raw) test scores: we identify this effect through an interaction with (raw) wages dispersion. ${ }^{40}$ For comparability, all tables report standardized coefficients of the explanatory variables. We show results based on three alternative measures of dispersion: the 95-5 interpercentile range divided by the average in column (1), the Gini relative mean difference (i.e. twice the Gini coefficient) in column (2) and the coefficient of variation in column (3). ${ }^{41}$ Columns (1)-(3) add exporter, importer and industry dummies to our variables of interest; columns (4)-(6) include theoretically consistent exporter and importer-industry dummies, along with a vector of bilateral trade barriers described

\footnotetext{
${ }^{39}$ We use the Canadian Labor Force Survey data for May 2000. Details of this exercise are available upon request.

${ }^{40}$ Raw measures are not purged of the effect of observable characteristics.

${ }^{41}$ We note that all three measures have a common structure in that the numerator is a measure of dispersion (the 95-5 interpercentile range, the standard deviation and the Gini mean difference) while the denominator is the average of the variable. Since we are using the logarithm of variables, the reason why we employ measures of dispersion divided by the average is not for rescaling, but rather to parsimoniously control for the effect that the interaction of the averages might have on trade flows.
} 
in the Appendix.

In all specifications the estimated interaction $W a g e D i s p_{i} \times S k i l l D i s p_{H}$ shows a positive effect on exports, significant throughout at the $5 \%$ level. The reported coefficients imply that a one standard deviation increase in the value of the interaction raises log exports by anywhere between $10.7 \%$ and $19.3 \%$ standard deviations. ${ }^{42}$ We postpone a detailed discussion of magnitudes to later in this Section.

Table 4 reproduces the structure of table 3 in terms of controls, but it separately reports the effect of the interaction WageDisp $p_{i} \times S k i l l D i s p_{H}$ (where the measure of dispersion is not divided by the average), as well as those of the interaction of average scores and average wages, WageMean $_{i} \times$ SkillMean $_{H}$, and of the other two interactions, WageDisp ${ }_{i} \times$ SkillMean $_{H}$ and WageMean $_{i} \times$ SkillDisp $_{H}$. The interaction of the averages is expected to capture standard factor proportions effects: on average, countries with more skilled workers specialize in sectors that employ skilled workers and have higher average wages. The interaction WageMean $_{i} \times \operatorname{SkillDisp}_{H}$ is a flexible way to control for possible bias, due to differences in sectoral average wages, in the estimated effect of our interaction of interest. The interaction $W$ age Disp $p_{i} \times S k i l l M e a n_{H}$ plays a similar role. ${ }^{43}$ In general, columns (1)-(6) suggest that the coefficient of WageDisp $p_{i} \times S k i l l D i s p_{H}$ is robust to the inclusion of all interactions: all estimates are similar to the ones in table 3 and, with the exception of one case, significant at the $5 \%$ level. As for the other interactions, as expected WageMean $_{i} \times$ SkillMean $_{H}$ has a strong and positive impact on trade flows. Moreover WageMean $_{i} \times$ SkillDisp $_{H}$ is consistently positive, significant and large, while WageDisp $_{i} \times \operatorname{SkillMean}_{H}$ is positive, but not always significant, particularly in columns (1)-(3).

\footnotetext{
${ }^{42}$ In regressions we do not report, we interacted all measures of dispersion for wages and scores with one another obtaining results qualitatively and quantitatively similar to columns (1)-(6).

${ }^{43}$ This interaction relates to the theoretical prediction that increases in average skills not resulting from proportional changes also have an effect on comparative advantage. This effect depends on the degree of complementarity, approximated by WageDisp .
} 
Table 5 has a structure similar to tables 3 and 4, but it employs measures of residual wage and residual skill dispersion, as defined in sections 4.2.2 and 4.2.1. In this specification we do not control for averages, since they are zero by construction. The measures of dispersion employed in table 5 are: the 95-5 interpercentile range in column (1) and (4), the Gini mean difference in column (2) and (5) and the standard deviation in column (3) and (6). Again, we find that WageDisp $\times$ $\times$ SkillDisp $_{H}$ has a positive and significant effect on exports. ${ }^{44}$ We note that the magnitudes are similar to the coefficients in tables 3 and 4, indicating a substantial degree of robustness in our results. The standardized coefficient of WageDisp $p_{i} \times$ SkillDisp $_{H}$ varies between $10.4 \%$ and $23 \%$ in the six specifications.

Finally, we employ the estimated coefficients to gauge the economic magnitude of this source of comparative advantage. The standardized coefficient of $W a g e D i s p_{i} \times S k i l l D i s p_{H}$ is similar across specifications. Our baseline estimate is 0.23 (column 4, table 5). Consider two countries, the US and Canada, and two sectors, 'computers' and 'paper mills'. These countries and sectors are chosen because, going from paper mills's WageDisp interacted with Canada's SkillDisp to computers's WageDisp interacted with the US SkillDisp, the interaction WageDisp $p_{i} \times S_{k i l l D i s p_{H}}$ increases by approximately one standard deviation. Since the standard deviation of log exports is 2.204 the relative ratios of US and Canada's exports to an average importer $c$ in the two sectors are given by $e^{0.23 \times 2.20}$, that is:

$$
\frac{\frac{X_{U S c}(\text { computers })}{X_{C A N A D A c}(\text { computers })}}{\frac{X_{U S c}(\text { paper })}{X_{C A N A D A c}(\text { paper })}}=1.66
$$

This implies that, averaging across destination markets, the US exports of computers relative to Canada are $66 \%$ higher than the US exports of paper products relative to Canada (this number is $26 \%$ if we employ the lowest estimate in table 5).

\footnotetext{
${ }^{44}$ In column (6) the interaction is signicant at the $6 \%$ level.
} 


\subsection{Identification and Robustness}

In this section we discuss some potential issues related to the identification of the effects quantified in tables 3,4 and 5 .

\subsubsection{The Extensive Margin of Trade: Selection}

Tables 3, 4, and 5 report estimation results which do not take into account the fact that a substantial fraction of bilateral trade flows are zero and that trade flows reflect both an intensive margin (the amount exported by each firm) and an extensive margin (the number of firms exporting, possibly zero). The estimation of (12) requires excluding observations for countries which do not trade in specific industries. These amount to $66.5 \%$ of the sample. As discussed in HMR, selection of trading partners induces a negative correlation between observed and unobserved trade barriers $\left(d_{H F}\right.$ and $\left.u_{H F}\right)$ that might bias OLS estimates in (12), including $\beta$.

In order to correct for selection bias, we implement a two-step estimation procedure: in the first step we account for the discrete export decision using a linear probability model and obtain the predicted probabilities of observing positive exports, $\widehat{\varphi_{H F i}}$; in the second stage, equation (12) is estimated including a flexible polynomial of degree four in $\widehat{\varphi_{H F i}}$ to control for selection bias. ${ }^{45}$ For identification not to rely on the non-linearity of $\widehat{\varphi_{H F i}}$ one needs to identify a source of variation which affects the discrete choice of engaging in exports without changing the intensity of trade flows. HMR argue that cross-country variation in start-up regulation costs likely relates to the decision to export, and it has no bearing on the intensive margin. The economic rationale lies in the fact that start-up costs in the exporting country, as well as in the importing one, affect fixed rather than variable costs of trade. Different forces can be at work and the nature and strength of this effect

\footnotetext{
${ }^{45}$ We favor using a linear probability model in the first stage since its two most common alternatives, probit and logit models, suffer different problems in the current application. The probit model with fixed effects yields inconsistent estimates. In turn, estimating a fixed effects logit becomes computationally very costly due to the large number of fixed effects required by our specification of equation (12).
} 
may depend on characteristics of both exporting and importing countries. For example, HMR find that start-up regulation costs are an effective predictor of the extensive export decision and that the interaction between home and foreign regulation costs has a negative gradient on the likelihood to export. On the other hand, De Groot et al. (2004) show that differences in institutional factors, including differences in regulation and red tape, have large effects on trade flows; their work unveils an alternative channel through which regulation can affect trade, and stresses the importance of 'similarity' in institutional frameworks.

An analysis of the first-stage bilateral export decisions (see table 7 in the Appendix) uncovers strong effects of regulation costs. We use exporter-importer interactions of three proxies of regulation costs: the number of days $\left(\operatorname{RegDays}_{H} \times \operatorname{RegDays}_{F}\right)$, number of legal procedures $\left(\operatorname{RegProc}_{H} \times\right.$ $\left.\operatorname{RegProc}_{F}\right)$ and relative cost, as a percentage of GDP per capita $\left(\operatorname{RegProc}_{H} \times \operatorname{RegProc}_{F}\right)$, for an entrepreneur to start operating a business. ${ }^{46}$ We find that these proxies are significant predictors of selection into exporting and that the direction of the effect changes by country characteristics; in fact, as might be expected, we find that regulatory costs tend to have a direct negative effect on export choices, but also that relative differences across countries do matter, and can lead to positive interaction effects. ${ }^{47}$

In table 6 we report the second-stage obtained using the selection correction. To facilitate comparison, column (1) of table 6 is identical to column (4) of table 5 , which is the baseline result. Throughout this table we employ only one of the three measures of dispersion, i.e. the standard deviation. ${ }^{48}$ Columns (2)-(6) report the second stage of the selection-corrected estimation. Column (2) documents the robustness of the effect associated to the interaction $W a g e D i s p_{i} \times S k i l l D i s p_{H}$ :

\footnotetext{
${ }^{46}$ To test the overidentifying restrictions we performed a Hausman test comparing second stage estimates using all three instruments to the corresponding estimates using only a subset of them. We tested all possible combinations of exclusion restrictions and in no case could we reject the null hypothesis that they are valid and, therefore, estimates with different restrictions only differ as a result of sampling error.

${ }^{47}$ Additional details available from the authors.

${ }^{48}$ The same qualitative results emerge if we employ the other two measures of dispersion.
} 
the standardized coefficient is essentially unchanged at 0.212 .

\subsubsection{Omitted Determinants of Comparative Advantage}

A second potential source of bias is due to the omission of other determinants of comparative advantage, possibly correlated to our variable of interest. Suppose that the true model includes an additional term $n_{i} Z_{H}$. If $W a g e D i s p_{i}$ were correlated with $n_{i}$ and $S k i l l D i s p_{H}$ were correlated with $Z_{H}$, the OLS estimate of $\beta$ in equation (12) would be inconsistent. As an example, industries with lower dispersion of wages tend to be capital intensive. Similarly, exporters with low skill dispersion tend to be relatively abundant in aggregate physical capital. ${ }^{49}$ In this case, comparative advantage driven by skill dispersion is correlated with comparative advantage deriving from standard factor proportions theory.

Columns (3) to (5) of table 6 show that the estimated effect of the interaction WageDisp $_{i} \times$ SkillDisp $p_{H}$ is robust to a number of controls for other potential determinants of comparative advantage. Column (3) introduces controls for standard Heckscher-Ohlin sources of comparative advantage: the interaction of factor endowment of a country (in particular human capital, SkillEndow ${ }_{H}$ and physical capital, $K$ Endow $_{H}$ ) and factor intensity of the sector (human capital SkillIntens $s_{i}$ and physical capital, KIntens $s_{i}$ ), as in Romalis (2004). Looking at $95 \%$ confidence intervals, the impact on trade flows of our variable of interest WageDisp $_{i} \times S k i l l D i s p_{H}$ is quantitatively similar to the interaction KIntens $_{i} \times$ KEndow $_{H}$ and slightly larger than SkillIntens $s_{i} \times$ SkillEndow $_{H}$. In column (4) we control for the interaction between the standard deviation of firm size within industry $i$, FirmDisp $_{i}$, and SkillDisp $_{H}$. With this interaction we explore a potential alternative mechanism that might be driving our result. In particular, if entry in sectors with high firm size dispersion is

\footnotetext{
${ }^{49}$ In our dataset, the correlation between the coefficient of dispersion of residual wages and physical capital intensity across industries is -0.511. In turn, the correlation between the standard deviation of residual IALS scores and physical capital abundance across exporters is -0.524 .
} 
higher in countries with high skill dispersion (because of higher possibility of assortative matching between firms and workers) then we would expect a positive effect of FirmDisp $_{i} \times$ SkillDisp $_{H}$ on trade flows. However, this alternative control does not substantially affect the magnitude and significance of our variable of interest and has very little explanatory power for trade flows. In column (5) we introduce the share of individual wages that are top-coded within an industry, TopCode , $_{\text {, }}$ interacted with $S k i l l D i s p_{H}$, and we show that our result is not driven by the fact that some sectors rely on 'super-stars' (those sectors that have a high share of top-coded wages). This suggests that more than one aspect of the dispersion of the distribution of wages is driving the result, and the overall shape of the distribution seems to be better captured by broader measures of dispersion.

\subsubsection{Reverse Causality}

Finally, WageDisp $i$ and SkillDisp $p_{H}$ might be partly influenced by the pattern of international trade, potentially resulting in reverse causality. We explore this possibility by examining the relationship between each of these two variables and the error term $\varepsilon_{H F i}$. The orthogonality condition needed for consistent estimation of $\beta$ in equation (12) is:

$$
E\left(\text { WageDisp }_{s} \times \text { SkillDisp }_{c} \times \varepsilon_{H F i}\right)=0 \quad \forall s, c
$$

By the Law of Iterated Expectations, a sufficient condition to obtain identification is:

$$
E\left(\text { WageDisp }_{s} \times \varepsilon_{H F i} \mid S k i l l D i s p_{c}\right)=0 \quad \forall s, c
$$

which requires that, for every exporter in our sample, within-industry wage dispersion be uncorre-

lated with unobserved determinants of trade. For example, a violation of (17) would arise if $\varepsilon_{H F i}$ 
contained the unobserved share of exporting firms in a given sector in $H$ and the proportion of exporters varied across industries and importers. In a model with heterogeneous firms, Helpman et al. (2008a) show that within-industry wage dispersion is a function of the proportion of firms exporting in the industry since, on average, exporters pay higher wages than non-exporters. ${ }^{50}$ However, as shown in HMR, the correction for self-selection into the export market discussed in section 4.4.1 effectively removes this potential bias.

Furthermore, since we measure wage dispersion at the industry level using U.S. data, we can check the robustness of our estimates by removing the U.S. from our set of exporters. To the extent that the U.S. wage structure is not significantly affected by bilateral trade flows between other countries, this procedure substantially decreases the likelihood of feedback effects running from trade flows to WageDisp . Column (6) in table 6 shows that, also in this case, the coefficient of our interaction of interest maintains the same magnitude and significance.

An alternative sufficient condition that guarantees (16), and therefore identification of $\beta$, is

$$
E\left(\text { SkillDisp }_{c} \times \varepsilon_{H F i} \mid W a g e \operatorname{Disp}_{s}\right)=0 \quad \forall s, c
$$

which means that skill dispersion in every exporting country is uncorrelated with the error term $\varepsilon_{H F i}$.. This condition is satisfied if unobserved exporting opportunities captured in $\varepsilon_{H F i}$ are not significantly related to the dispersion, and overall distribution, of residual skills in a country. There are several reasons to believe that this is plausible. First, the unobserved exporting opportunities $\varepsilon_{H F i}$ must occur at levels other than exporter or importer-industry, which are already captured by our set of dummies. Moreover, since our skill dispersion measures pre-date trade flows by several years, the link between $\varepsilon_{H F i}$ and $S k i l l D i s p_{c}$ introduces bias only if: (i) $\varepsilon_{H F i}$ is a highly persistent

\footnotetext{
${ }^{50}$ Exporters do pay higher wages. See, for example, Bernard et al. (1995) and Bernard and Jensen (1997).
} 
shock to exporting opportunities which is not captured by our dummies and also affects the longterm, 'residual' skill distribution, and (ii) the skill distribution reacts very quickly in response to export shocks. In this respect Glaeser et al. (2004) show that the education system is a slowchanging characteristic of a country. However, skill dispersion is not only the product of the formal education system, but may change after school through on-the-job training. A number of papers have established the relatively limited impact of on-the-job training on the overall level of human capital. ${ }^{51}$ Nevertheless, we explicitly account for the possibility that re-training is triggered by exporting opportunities through the inclusion, in the derivation of residual skills, of a control for whether a worker was re-trained in the previous year.

\section{Conclusions}

Relative differences in the distribution of production factors are central to the classical theory of international trade. The Heckscher-Ohlin-Samuelson factor proportion model stresses the idea that differences in factor endowments play a major role in predicting trade flows. Comparative advantage is associated with relatively abundant factors of production: the 'average' endowment of some important factor can be a driving force in determining international specialization. In this paper we push this idea further and argue that the whole distribution of factor endowments, rather than just their average, can help rationalize observed trade flows. We focus on human capital and skills, and use industry-level trade data, to show that factors' dispersion accounts for as much as relative factors' proportions in the determination of trade flows.

First, we develop a theoretical framework where, because of frictions in the labor market and ex-ante unobservable skills, workers and firms are randomly matched. The skill distribution matters

\footnotetext{
${ }^{51}$ See discussion in Carneiro and Heckman (2003) and Adda et al. (2006).
} 
for different sectors because some industries are more capable to substitute workers of different skill than others. All sectors inherit the distribution of (unobserved) skills in the country's population and, as a result, firms in sectors with higher complementarity are relatively more productive in countries with lower skill dispersion. Our model provides an observable proxy for the otherwise unobservable degree of complementarity among workers' skills, that is the dispersion of wages at the industry level. Detailed data on industry-level bilateral trade flows reveal that countries with higher skill dispersion specialize in high wage dispersion sectors. This empirical finding is robust to a battery of controls and indicates that the dispersion of human capital is not only statistically significant, but also quantitatively large: in fact we find that the magnitude of its effect on trade flows is comparable to that of the aggregate endowment of human capital in a country. Two remarks about the interpretation of our evidence are in order.

First, although we provide a theoretical framework alternative to GM's, our empirical results are not inconsistent with their model: we find that countries with high skill dispersion specialize in sectors with high wage dispersion. In our model we relate this to technology, in particular the degree of complementarity among workers' abilities, which is the only determinant of wage dispersion, since every sector inherits the distribution of skills in the country's population and the labor market is characterized by substantial frictions that prevent workers of identical skills from earning identical wages. Conversely, in GM, labor markets are perfectly competitive and any differences in the sectoral wage distribution is due exclusively to industries employing workers of different skills. We expect that a multi-country, multi-sector extension of GM would have testable implications similar to ours. We are not aware of such an extension and we believe it would be non-trivial.

Second, we hypothesize that a Heckscher-Ohlin-Samuelson model of factor proportions with 
a large number of factors and different factor intensities across sectors would potentially yield testable implications similar to our model. Our results indicate that such a model should encompass a much finer level of disaggregation of factors than Heckscher-Ohlin-Samuelson-type models and their empirical tests have employed so far. ${ }^{52}$

Finally, the theoretical framework developed in this paper has implications for the impact of trade on overall wage inequality, which are beyond the scope of this study. Our model, taken at face value, implies that a more disperse skill distribution does not just have a direct effect on the income distribution, but also an indirect effect, as countries with higher skill dispersion specialize in sectors with high wage dispersion. Although we consider this effect intriguing, we are aware that our static, stylized description of the labor market is not sophisticated enough to account for alternative determinants of overall inequality.

\section{A Appendix - Proofs}

\section{A.1 Proof of Proposition 1}

By definition of log-supermodularity we need to prove that, if $g\left(a, c^{\prime}\right)$ is a mean-preserving spread of $g(a, c)$ then:

$$
\frac{\partial \log A(\lambda, c)}{\partial \lambda} \leq \frac{\partial \log A\left(\lambda, c^{\prime}\right)}{\partial \lambda}
$$

The partial derivative has the following expression:

$$
\frac{\partial \log A(\lambda, c)}{\partial \lambda}=\frac{1}{\lambda} \frac{\int a^{\lambda} \log a g(a, c) d a}{\int a^{\lambda} g(a, c) d a}-\frac{1}{\lambda^{2}} \log \left(\int a^{\lambda} g(a, c) d a\right)
$$

A mean-preserving spread of $g(a, c)$ increases the second term of the right-hand side of (A-1) by definition, since $a^{\lambda}$ is a concave function. A sufficient condition for the first term of $(\mathrm{A}-1)$ to increase with a mean-preserving spread in $g(a, c)$ is that $k(a)=a^{\lambda} \log a$ is a convex function which is verified if its second derivative with respect to $a$ is positive for every value of $a$. i.e. $\log a<\frac{2 \lambda-1}{(1-\lambda) \lambda}$. Since the right-hand side of this inequality is continuous and increasing in $\lambda$, it is equal to zero for $\lambda=\frac{1}{2}$ and $\lim _{\lambda \rightarrow 1} \frac{2 \lambda-1}{(1-\lambda) \lambda}=\infty$ then, if $a$ is bounded above by $a_{\max }$, then there exists a value $\bar{\lambda}<1$ such that $\log a_{\max }=\frac{2 \bar{\lambda}-1}{(1-\bar{\lambda}) \bar{\lambda}}$. If $\lambda>\bar{\lambda}$ then $\frac{\partial \log A(\lambda, c)}{\partial \lambda}$ increases with a mean preserving spread of $g(a, c)$.

\footnotetext{
${ }^{52}$ Tests of the factor proportions theory typically involve a dichotomous classification of workers into production and non-production, or college and non-college educated.
} 


\section{A.2 Proof of Proposition 2}

(i) Pareto Distribution - Under the assumption that skills follow a Pareto distribution with mean $\mu$ and standard deviation $\sigma, A$ takes the following expression: ${ }^{53}$

$$
A=\frac{\mu^{2}+\sigma^{2}-\sigma \sqrt{\mu^{2}+\sigma^{2}}}{\mu}\left(\frac{\sigma+\sqrt{\mu^{2}+\sigma^{2}}}{\sigma+\sqrt{\mu^{2}+\sigma^{2}}-\lambda \sigma}\right)^{\frac{1}{\lambda}} .
$$

Since $A$ is twice differentiable in $\sigma$ and $\lambda$, the result in Proposition 3 is equivalent to $A$ being $\log$-supermodular in $\lambda$ and $\sigma$, that is $\frac{\partial^{2} \log A}{\partial \sigma \partial \lambda}>0$. The expression for the cross partial derivative is the following:

$$
\frac{\partial^{2} \log A}{\partial \sigma \partial \lambda}=\frac{\sigma\left(\sqrt{\mu^{2}+\sigma^{2}}-\sigma\right)}{\sqrt{\mu^{2}+\sigma^{2}}\left[\sigma(1-\lambda)+\sqrt{\mu^{2}+\sigma^{2}}\right]}
$$

and $\lambda<1$ so $A$ is log-supermodular in $\lambda$ and $\sigma$.

(ii) Log-Normal Distribution - If the distribution of skills $a$ is lognormal on the support $[0, \infty]$ with mean $\mu$ and standard deviation $\sigma$ then $A$ takes the following form:

$$
A=e^{\log \mu-\frac{1-\lambda}{2} \log \left(\frac{\sigma^{2}}{\mu^{2}}+1\right)}
$$

It is easy to show that under this distribution, $A$ is log-supermodular since the following expression is always positive:

$$
\frac{\partial^{2} \log A}{\partial \sigma \partial \lambda}=\frac{\sigma}{\mu^{2}+\sigma^{2}}
$$

\section{A.3 Derivation of Firm Output, Prices and Revenues in All Markets}

In this section we provide details about the solution to the firm problem.

Derivation of revenues (4)

First, we show how to derive the expression for total revenues in (4). Total revenues of a firm in Home are given by:

$$
r_{H}=B_{H} y_{H H}^{\frac{\sigma-1}{\sigma}}+B_{F} y_{H F}^{\frac{\sigma-1}{\sigma}} \tau^{\frac{1-\sigma}{\sigma}}
$$

\footnotetext{
${ }^{53}$ The Pareto distribution is characterized by a shape parameter $k$ and location parameter $a_{\min }$, i.e. the cumulative distribution of ability is given by $G(a)=1-\left(\frac{a_{\min }}{a}\right)^{k}$ with $a_{\min }>0$ and $k>2$. We could have written $A$ as a function of those parameters:$$
A=a_{\min }\left(\frac{k}{k-\lambda}\right)^{\frac{1}{\lambda}}
$$

Since we are interested in a mean-preserving increase in variance, we express the $A$ as a function of $\mu$ and $\sigma$, which are related to shape and location parameters according to the following equations:

$$
a_{\min }=\frac{\mu^{2}+\sigma^{2}-\sigma \sqrt{\mu^{2}+\sigma^{2}}}{\mu}
$$$$
k=\frac{\sigma+\sqrt{\mu^{2}+\sigma^{2}}}{\sigma}
$$ 
For a profit-maximizing firm marginal revenues have to be equal across markets. Rearranging the equality of marginal revenue condition leads to the following:

$$
\frac{y_{H H}}{y_{H F}}=\left(\frac{B_{H}}{B_{F}}\right)^{\sigma} \tau^{\sigma-1}
$$

From (A-4) $y_{H H}$ can be expressed as a function of $y_{H F}$ and replaced in (A-3) to find:

$$
r_{H}=B_{F} y_{H F}^{-\frac{1}{\sigma}} \tau^{\frac{1-\sigma}{\sigma}}\left(y_{H H}+y_{H F}\right)
$$

From (A-5) and its analogous for $y_{H H}$ we can find the two following equations:

$$
\begin{aligned}
& y_{H H}=r_{H}^{-\sigma} B_{H}^{\sigma}\left(y_{H H}+y_{H F}\right)^{\sigma} \\
& y_{H F}=r_{H}^{-\sigma} B_{F}^{\sigma}\left(y_{H H}+y_{H F}\right)^{\sigma} \tau^{1-\sigma}
\end{aligned}
$$

Adding up (A-6) and (A-7) and rearranging them leads to the expression for revenues reported in (4):

$$
r=\left(y_{H H}+y_{H F}\right)^{\frac{\sigma-1}{\sigma}}\left(B_{H}^{\sigma}+B_{F}^{\sigma} \tau^{1-\sigma}\right)^{\frac{1}{\sigma}}
$$

Derivation of output and prices

The first order condition of problem (6) can be written as a function of revenues $r_{H}$ as follows:

$$
s \frac{\sigma-1}{\sigma \lambda b} r_{H}=h_{H}
$$

This first order condition, together with the zero profit condition derived from free entry, implies:

$$
s r_{H}-b h_{H}-f=0
$$

delivers total revenues and employment:

$$
\begin{aligned}
r_{H} & =\frac{f \sigma \lambda}{s(\sigma \lambda-\sigma+1)} \\
h_{H} & =\frac{f(\sigma-1)}{b(\sigma \lambda-\sigma+1)}
\end{aligned}
$$

Given the production function, the expression for total output follows:

$$
y_{H}=A(\lambda, H)\left[\frac{f(\sigma-1)}{b(\sigma \lambda-\sigma+1)}\right]^{\frac{1}{\lambda}}
$$

Next, we determine how output is divided across the domestic and export market. We employ (A-6) and (A-7) and their analogous for the Foreign firm to find the relative output of firms selling in the same market:

$$
\begin{aligned}
\frac{y_{H H}}{y_{F H}} & =\frac{r_{H}^{-\sigma}\left(y_{H H}+y_{H F}\right)^{\sigma}}{r_{F}^{-\sigma}\left(y_{F F}+y_{F H}\right)^{\sigma} \tau^{1-\sigma}} \\
\frac{y_{F F}}{y_{H F}} & =\frac{r_{F}^{-\sigma}\left(y_{F F}+y_{F H}\right)^{\sigma}}{r_{H}^{-\sigma}\left(y_{H H}+y_{H F}\right)^{\sigma} \tau^{1-\sigma}}
\end{aligned}
$$


The expressions above can be simplified using the fact that total revenues are constant in a given sector: $r_{H}=r_{F}=r$. Together with (A-8) and its foreign equivalent, (A-9) and (A-10) deliver the amount of output sold by a Foreign and a Home firm in every market. The amounts of output sold in the two markets by a Home firm are given by:

$$
\begin{aligned}
& y_{H H}=\frac{\phi A(\lambda, H)}{1-\rho^{2}}\left[1-\rho\left(\frac{A(\lambda, H)}{A(\lambda, F)}\right)^{\sigma-1}\right] \\
& y_{H F}=\frac{\phi \rho A(\lambda, H)}{1-\rho^{2}}\left[\left(\frac{A(\lambda, H)}{A(\lambda, F)}\right)^{\sigma-1}-\rho\right]
\end{aligned}
$$

where $\rho=\tau^{1-\sigma}$, while the corresponding Foreign firm expressions are:

$$
\begin{aligned}
& y_{F F}=\frac{\phi A(\lambda, F)}{1-\rho^{2}}\left[1-\rho\left(\frac{A(\lambda, H)}{A(\lambda, F)}\right)^{1-\sigma}\right] \\
& y_{F H}=\frac{\phi \rho A(\lambda, F)}{1-\rho^{2}}\left[\left(\frac{A(\lambda, F)}{A(\lambda, H)}\right)^{\sigma-1}-\rho\right]
\end{aligned}
$$

Finally we derive relative revenues for a Home and a Foreign firm in a given market (9) by expressing

it first as a function of relative output $\frac{r_{H F}}{r_{F F}}=\left(\frac{y_{H F}}{y_{F F}}\right)^{\frac{\sigma-1}{\sigma}} \tau^{\frac{1-\sigma}{\sigma}}$, and then replacing the expressions for $y_{H F}$ and $y_{F F}$.

\section{A.4 Derivation of the Mass of Firms}

Having determined the revenues of a firm in each market, the mass of firms in each country has to be such that, total expenditure on good $\lambda$ in a given country is equal to total revenues accruing to all firms operating in that market. The two equations below express these equilibrium conditions for sector $\lambda$ :

$$
\begin{aligned}
\alpha(\lambda) L_{H} & =M_{H}(\lambda) r_{H H}(\lambda)+M_{F}(\lambda) r_{F H}(\lambda) \\
\alpha(\lambda) L_{F} & =M_{F}(\lambda) r_{F F}(\lambda)+M_{H}(\lambda) r_{H F}(\lambda)
\end{aligned}
$$

It is convenient to rewrite conditions $(\mathrm{A}-15)$ and $(\mathrm{A}-16)$ as a function of output, rather than of revenues:

$$
\begin{aligned}
\alpha L^{H} & =M_{H} \frac{\gamma}{\phi A(\lambda, H)} y_{H H}+M_{F} \frac{\gamma}{\phi A(\lambda, F)} y_{F H}, \\
\alpha L^{F} & =M_{F} \frac{\gamma}{\phi A(\lambda, F)} y_{F F}+M_{H} \frac{\gamma}{\phi A(\lambda, H)} y_{H F} .
\end{aligned}
$$

The solution to this linear system is given by the following expressions for $M_{H}$ and $M_{F}$ :

$$
\begin{aligned}
& M_{H}=A(\lambda, H) \frac{\alpha \phi\left(L_{H} y_{F F}-L_{F} y_{F H}\right)}{\gamma\left(y_{F F} y_{H H}-y_{H F} y_{F H}\right)}, \\
& M_{F}=A(\lambda, F) \frac{\alpha \phi\left(L_{F} y_{H H}-L_{H} y_{H F}\right)}{\gamma\left(y_{F F} y_{H H}-y_{H F} y_{F H}\right)} .
\end{aligned}
$$


First, we show that the denominator of $M_{H}$ and $M_{F}$ is always positive. Define Home productivity advantage $z(\lambda)=\frac{A(\lambda, H)}{A(\lambda, F)}$. The denominator is positive if and only if $\frac{y_{H H}}{y_{F H}}>\frac{y_{H F}}{y_{F F}}$, a condition we can rewrite as $z^{\sigma} \frac{1}{\rho}>z^{\sigma} \rho$ and that is always satisfied since $\rho<1$.

The mass of Home firms $M_{H}$ is positive if and only if $L_{H} y_{F F}-L_{F} y_{F H}>0$. This condition places a lower bound on the relative population, since $M_{H}>0$ if and only if:

$$
\eta>\frac{\rho\left(\frac{1}{z^{\sigma-1}}-\rho\right)}{1-\frac{\rho}{z^{\sigma-1}}}=\eta_{\text {low }}
$$

Equivalently, $M_{F}$ is positive if and only if $L_{F} y_{H H}-L_{H} y_{H F}>0$, a condition that places an upper bound on the relative population $\eta$, i.e. $M_{F}>0$ if and only if:

$$
\eta<\frac{1-\rho z^{\sigma-1}}{\rho\left(z^{\sigma-1}-\rho\right)}=\eta_{u p}
$$

Both $\eta_{l o w}$ and $\eta_{u p}$ are positive under the condition that we imposed in order to guarantee that a positive amount of output is produced for every market: $\rho<z^{\sigma-1}<\frac{1}{\rho}$.

\section{A.5 Proof of Proposition 3}

We define the mass of Home relative to Foreign firms in sector $\lambda$ as $m(\lambda) \equiv \frac{M_{H}}{M_{F}}$. We investigate how $m$ changes with $z$, assuming that we are operating in the parameter space where $\eta_{\text {low }}<\eta<\eta_{u p}$. We rewrite the relative mass of firms, using (A-17), (A-18), the expressions for Home firm outputs, (A-11) and (A-12), and the corresponding expressions for the Foreign firm:

$$
m=\frac{z^{1-\sigma}(1+\eta) \rho-\left(\eta+\rho^{2}\right)}{z^{\sigma-1}(1+\eta) \rho-\left(1+\eta \rho^{2}\right)}
$$

The first derivative of $m$ with respect to $z$ takes the following form:

$$
\frac{\partial m}{\partial z}=\frac{1}{z^{\sigma+2}}(\sigma-1)(1+\eta) \frac{-2 z^{1+\sigma}(1+\eta) \rho+z^{2 \sigma}\left(\eta+\rho^{2}\right)+z^{2}\left(1+\eta \rho^{2}\right)}{\left(\rho z^{\sigma-1}-\eta \rho^{2}+\eta \rho z^{\sigma-1}-1\right)^{2}}
$$

This derivative is positive if the numerator is positive and the numerator can be divided in two parts, which we show are both positive. The first part, denoted by $\psi_{1}$ is:

$$
\psi_{1}=-z^{1+\sigma}(1+\eta) \rho+z^{2 \sigma}\left(\eta+\rho^{2}\right),
$$

while the second part denoted by $\psi_{2}$ is:

$$
\psi_{2}=-h z^{1+\sigma}(1+\eta) \rho+z^{2}\left(1+\eta \rho^{2}\right) .
$$

It is straightforward to show that $\psi_{1}>0$ if and only if $\eta>\eta_{\text {low }}$ and that $\psi_{2}>0$ if and only if $\eta<\eta_{\text {up }}$, conditions we have imposed throughout.

\section{A.6 Proof of Proposition 4}

The result follows directly since we have proven that both components of relative sales (10), relative revenues per firm $\frac{r_{F H}(\lambda)}{r_{H H}(\lambda)}$ and relative mass of firms $\frac{M_{F}(\lambda)}{M_{H}(\lambda)}$ are increasing in relative productivity 
$\frac{A(\lambda, F)}{A(\lambda, H)}$ (see (9) and Proposition 3) and relative productivity depends the degree of complementarity $\lambda$ (proxied by the dispersion of wages according to Proposition 6) and the dispersion of skills according to the discussion in Section 2.4.

\section{A.7 Proof of Proposition 5}

Since the derivation is analogous to the two-country case we simply report the expression relative revenues: $: 54$

$$
\frac{r_{H F}}{r_{G F}}=\left(\frac{A(\lambda, H)}{A(\lambda, G)}\right)^{\sigma-1}\left(\frac{\tau_{H F}}{\tau_{G F}}\right)^{1-\sigma} .
$$

It follows that, if the relative mass of firms is non-decreasing in relative productivity, relative exports are higher in comparative advantage sectors, similarly to the two-country case in Proposition 4.

\section{A.8 Derivation of the Shapley Value}

In this section we provide details on how to derive the share of revenues accruing to the firm and the wages paid to workers. Stole and Zwiebel (1996) have proved the equivalence of their bargaining solution to the Shapley value of the corresponding cooperative game not only for the case of identical workers, but also for the case of heterogeneous workers, ${ }^{55}$ therefore we calculate the Shapley value directly. ${ }^{56}$ The Shapley value of the firm is heuristically derived as its marginal contribution averaged over all possible orderings of employees and the firm itself. The case of heterogeneous employees is easy to handle under our assumption of a continuum of workers because no matter how the firm is ordered, it is preceded by a mass of workers whose skill distribution mirrors the overall skill distribution in the workers population, so the only variable we have to keep track of is the mass of workers preceding the firm, define it $n$, which varies from zero to $h$. As discussed in Acemoglu et al. (2007), since the firm is an essential input its marginal contribution is equal to revenues when $n$ workers are employed in production $r_{H}(n)=\left(n^{\frac{1}{\lambda}} A\right)^{\frac{\sigma-1}{\sigma}} \Gamma_{H}$. The Shapley value of the firm $S_{\text {firm }}$ is therefore:

$$
S_{\text {firm }}=\int_{0}^{h} \frac{1}{h}\left(n^{\frac{1}{\lambda}} A\right)^{\frac{\sigma-1}{\sigma}} \Gamma_{H} d n=s r_{H}
$$

where $s$ is defined by (5). As discussed in Acemoglu et al. (2007) the share of revenues accruing to the firm depends on the curvature of the revenue function, due to characteristics of the demand function $(\sigma)$ and the production function $(\lambda)$.

In a similar fashion we calculate the Shapley value of a worker of skill $a$, by averaging its marginal contribution across all possible orderings. When a mass $n$ of workers is employed, revenues of the firm are:

$$
r(n)=\Gamma_{H}\left[\int_{a} a^{\lambda} n(a, c) d a\right]^{\frac{\sigma-1}{\sigma \lambda}}
$$

where $n(a, c)=n g(a, c)$. The marginal contribution of a worker of skills $a$ is given by the marginal revenue from an increase in the mass of workers of skill $a, n(a, c)$, conditional on the firm being

\footnotetext{
${ }^{54}$ Details are available from the authors upon request.

${ }^{55}$ See their Theorems 8 and 9, p. 393.

${ }^{56}$ The analogous of the Shapley value for a continuum of players is derived in Aumann and Shapley (1974).
} 
ordered before the worker (otherwise the marginal contribution is null):

$$
\frac{\partial r(n)}{\partial n(a)}=\Gamma_{H} \frac{\sigma-1}{\sigma \lambda}\left[\int_{a} n \tilde{g}(a) a^{\lambda} d a\right]^{\frac{\sigma-1}{\sigma \lambda}-1} a^{\lambda}
$$

The Shapley value and wage of worker of skill $a$ in industry $\lambda$ is:

$$
w(a, \lambda)=\frac{1}{h} \int_{o}^{h} \frac{n}{h} \frac{\partial r(n)}{\partial n(a)} d n=\Gamma_{H} A(\lambda, c)^{\frac{\sigma-1-\sigma \lambda}{\sigma}} \frac{\sigma-1}{\sigma-1+\sigma \lambda} h^{\frac{\sigma-1}{\sigma \lambda}-1} a^{\lambda}
$$

Since the average wage also differs across sectors, we normalize wages by the average wage in the sector $E[w(a, \lambda)]$. The normalized wage is denoted by $\widetilde{w}(a, \lambda)=\frac{w(a, \lambda)}{E[w(a, \lambda)]}$ and takes the following form:

$$
\widetilde{w}(a, \lambda)=\frac{a^{\lambda}}{E\left(a^{\lambda}\right)}
$$

\section{Proof of Proposition 6}

We consider three measures of wage dispersion:

(i) the Coefficient of Variation of wages $w(a, \lambda)$, directly related to the variance of the normalized wage $\widetilde{w}(a, \lambda), \operatorname{Var}(\widetilde{w}(a, \lambda))$, which is given by:

$$
\operatorname{Var}(\widetilde{w}(a, \lambda))=\frac{E\left(a^{2 \lambda}\right)}{E\left(a^{\lambda}\right)^{2}}-1,
$$

(ii) the Gini Coefficient, defined with respect to the Lorenz Curve for normalized wages at the sector level $\Lambda(w, \lambda)$,

(iii) the Inter-Percentile Ratio $I P R_{k j}$ defined as:

$$
I P R_{k j}=\frac{w_{k}}{w_{j}}
$$

where $w_{k}\left(w_{j}\right)$ is the wage of the worker at the $k^{t h}\left(j^{t h}\right)$ percentile of the sectoral wage distribution and $j<k$.

(i) Coefficient of Variation

Since the variance of normalized wages is equal to the square of the coefficient of variation we prove the result for the former. We start by rewriting (A-21) in an explicit form, dropping the country index $c$ to simplify notation:

$$
\operatorname{Var}(\widetilde{w}(a, \lambda))=\frac{\int a^{2 \lambda} \tilde{g}(a) d a}{\left(\int a^{\lambda} \tilde{g}(a) d a\right)^{2}}-1
$$

The derivative of (A-22) with respect to $\lambda$ is non-negative if an only if the following inequality is satisfied:

$$
\left(\int_{0}^{\infty} a^{2 \lambda} \log a \tilde{g}(a) d a\right)\left(\int_{0}^{\infty} a^{\lambda} \tilde{g}(a) d a\right) \geq\left(\int_{0}^{\infty} a^{\lambda} \log a \tilde{g}(a) d a\right)\left(\int_{0}^{\infty} a^{2 \lambda} \tilde{g}(a) d a\right)
$$


The left-hand side of (A-23), which we denote by $\Phi_{L}$ can be rewritten as:

$$
\Phi_{L}=\int_{0}^{\infty} \int_{0}^{\infty} a^{2 \lambda} \log a \tilde{g}(a) b^{\lambda} \tilde{g}(b) d a d b
$$

We can divide the region of integration in two parts, delimited by the 45 degree line in the plane $[0, \infty] \times[0, \infty]$. It follows that $\Phi_{L}$ can be rewritten as:

$$
\Phi_{L}=\int_{0}^{\infty}\left(\int_{0}^{a} b^{\lambda} \tilde{g}(b) d b\right) a^{2 \lambda} \log a \tilde{g}(a) d a+\int_{0}^{\infty}\left(\int_{a}^{\infty} b^{\lambda} \tilde{g}(b) d b\right) a^{2 \lambda} \log a \tilde{g}(a) d a
$$

We change the order of integration in the second component of $\Phi_{L}$ so that we can rewrite (A-24) it as:

$$
\Phi_{L}=\int_{0}^{\infty}\left(\int_{0}^{a} b^{\lambda} \tilde{g}(b) d b\right) a^{2 \lambda} \log a \tilde{g}(a) d a+\int_{0}^{\infty}\left(\int_{0}^{b} a^{2 \lambda} \log a \tilde{g}(a) d a\right) b^{\lambda} \tilde{g}(b) d b
$$

Finally, a change of variable in the second component of (A-25) allows us to express $\Phi_{L}$ as:

$$
\Phi_{L}=\int_{0}^{\infty}\left(\int_{0}^{a} b^{\lambda} \tilde{g}(b) d b\right) a^{2 \lambda} \log a \tilde{g}(a) d a+\int_{0}^{\infty}\left(\int_{0}^{a} b^{2 \lambda} \log b \tilde{g}(b) d b\right) a^{\lambda} \tilde{g}(a) d a
$$

If the same decomposition is performed on the right-hand side of (A-23) we can rewrite the inequality as follows:

$$
\int_{0}^{\infty}\left(\int_{0}^{a} a^{\lambda} b^{\lambda}\left[\left(a^{\lambda}-b^{\lambda}\right)(\log a-\log b)\right] \tilde{g}(b) \tilde{g}(a) d b\right) d a \geq 0
$$

which is always satisfied since $\left(a^{\lambda}-b^{\lambda}\right)(\log a-\log b) \geq 0$.

(ii) Gini Coefficient

We proceed by deriving the Lorenz Curve for sectoral normalized wages and showing that increasing $\lambda$ produces a downward shift in the curve at all points. This is a sufficient condition for the Gini coefficient to increase with an increase in $\lambda$. The Lorenz Curve $\Lambda(w, \lambda)$ of normalized wages in sector $\lambda$ is given by the following expression:

$$
\Lambda(w, \lambda)=\frac{\int_{0}^{w} a^{\lambda} \tilde{g}(a) d a}{\int_{0}^{\infty} a^{\lambda} \tilde{g}(a) d a}
$$

The first derivative with respect to $\lambda, \frac{\partial \Lambda(w, \lambda)}{\partial \lambda}$ is non-positive if and only if the following condition is satisfied $\forall w$ :

$$
\left(\int_{0}^{w} a^{\lambda} \log a \tilde{g}(a) d a\right)\left(\int_{0}^{\infty} b^{\lambda} \tilde{g}(b) d b\right) \leq\left(\int_{0}^{w} a^{\lambda} \tilde{g}(a) d a\right)\left(\int_{0}^{\infty} b^{\lambda} \log b \tilde{g}(b) d a\right)
$$

The region of integration can be divided into two part on both sides of the inequality, so that 
the inequality can be rewritten as follows:

$$
\begin{aligned}
& \left(\int_{0}^{w}\left(\int_{0}^{w} b^{\lambda} \tilde{g}(b) d b\right) a^{\lambda} \log a \tilde{g}(a) d a\right)+\int_{0}^{w}\left(\int_{w}^{\infty} b^{\lambda} \tilde{g}(b) d b\right) a^{\lambda} \log a \tilde{g}(a) d a \leq \\
& \left(\int_{0}^{w}\left(\int_{0}^{w} b^{\lambda} \log b \tilde{g}(b) d b\right) a^{\lambda} \tilde{g}(a) d a\right)+\int_{0}^{w}\left(\int_{w}^{\infty} b^{\lambda} \log b \tilde{g}(b) d b\right) a^{\lambda} \tilde{g}(a) d a
\end{aligned}
$$

Simplifying and factorizing leads to the following inequality:

$$
\int_{0}^{w} \int_{w}^{\infty} b^{\lambda} a^{\lambda}(\log a-\log b) \tilde{g}(b) \tilde{g}(a) d b d a \leq 0
$$

which is always satisfied since the range of integration of $a$ is $[0, w]$ while the range of integration of $b$ is $[w, \infty]$.

(iii) Inter-Percentile Ratio

It is straightforward to show that $I P R_{k j}$ increases with $\lambda$ since for any percentile the ratio of wages is given by:

$$
I P R_{k j}=\left(\frac{a_{k}}{a j}\right)^{\lambda}
$$

where $a_{k}\left(a_{j}\right)$ is the skill of the worker at the $k^{t h}\left(j^{t h}\right)$ percentile.

\section{B Appendix}

\section{B.1 Measuring Skill Dispersion}

The IALS microdata used for this paper was compiled by Statistics Canada using the original data sets collected between 1994 and 1998 in each of the participating countries. Tuijnman (2000) describes the three dimensions of literacy used to approximate skills. Prose literacy represents the knowledge and skills needed to understand and use information from texts including editorials, news stories, brochures and instruction manuals. Document literacy represents the knowledge and skills required to locate and use information contained in various formats, including job applications, payroll forms, transportation schedules, maps, tables and charts. Quantitative literacy represents the knowledge and skills required to apply arithmetic operations, either alone or sequentially, to numbers embedded in printed materials, such as balancing a chequebook, figuring out a tip, completing an order form or determining the amount of interest on a loan from an advertisement.

We employ the logarithm of scores (in conjunction with the log of wages) because the standard deviation of the logarithm of a random variable is scale invariant. When extracting residual scores in equation (14), using log-scores on the left-hand side is consistent with the common practice of obtaining residual wages from a regression of log-wages, as in equation (15). The results of the empirical analysis are qualitatively similar if we use levels instead of logs.

Only individuals participating in the labor market are included in the estimation of equation (15). These individuals were either: (i) employed or unemployed at some time in the 12 months previous to the survey or (ii) not searching for a job due to skill upgrading (school or work programs) or a temporary disability.

The right-hand side vector $X_{k H}$ in equation (14) includes a number of observable individual characteristics. Education is among them: we include indicators for 7 levels of educational at- 
tainment as defined by the International Standard Classification of Education (ISCED). The levels considered in IALS are: ISCED 0 Education preceding the first level; ISCED 1 Education at the first level; ISCED 2 Education at the second level, first stage; ISCED 3 Education at the second level, second stage; ISCED 5 Education at the third level, first stage (leads to an award not equivalent to a first university degree); ISCED 6 Education at the third level, first stage (leads to a first university degree or equivalent; ISCED 7 Education at the third level, second stage (leads to a postgraduate university degree or equivalent); ISCED 9 Education not definable by level. The vector $X_{k H}$ also includes 5 age intervals 16-25, 26-35, 36-45, 46-55 and 56-65, gender, immigrant status and participation in adult education or training programs 12 months prior to the survey date. The latter filters out the effect of skill upgrading on individual residual scores. As explained in section 4.4, this is an important issue for the identification of the effect of skill dispersion on trade flows as (unobserved) trade shocks might have an impact on aggregate skill dispersion by changing incentives for skill upgrading at the individual level. Residual scores $\widehat{\epsilon_{k H}}$ are constructed as $\widehat{\epsilon_{k H}}=\log \left(s_{k H}\right)-X_{k H} \widehat{\beta_{H}}$, where $\widehat{\beta_{H}}$ is estimated by OLS. Analyzing the R-squared of these country-by-country regressions, we find that the variation in residual scores $\widehat{\epsilon_{k H}}$ accounts for a minimum of $46 \%$ of the observed variation in log-scores in Canada, for a maximum of $83 \%$ in Germany and for $70 \%$ in Finland, the median country in the sample. ${ }^{57}$

As a result of focusing on log-scores, the scale of measurement of IALS scores does not affect the standard deviation of $\widehat{\epsilon_{k H}}$ or $\log \left(s_{k H}\right)$. Also note that, since $X_{k H}$ in (14) contains a constant, the distribution of $\widehat{\epsilon_{k H}}$ has the same (zero) mean in each country. For this reason, we do not normalize the standard deviation (or any inter-percentile range) by the mean in order to make cross-country comparisons of residual scores dispersion.

\section{B.2 Measuring Wage Dispersion}

Wage inequality measures are computed from a sample of full-time manufacturing workers, 16-65 years old, not living in group quarters, reporting positive wages and industry affiliation. ${ }^{58}$ Following Dahl (2002), individuals were considered as 'full-time employed' if in 1999 they: (i) were not enrolled full time in school, (ii) worked for pay for at least ten weeks, and (iii) earned an annual salary of at least 2,000 dollars. We focus on the log of weekly wages, calculated by dividing wage and salary income by annual weeks worked. We use weekly wages as opposed to hourly wages, because it requires fewer assumptions to calculate it. In the 2000 Census, hours worked are reported as 'usual hours'. Using this variable to convert weekly wages into hourly wages would almost certainly result in the introduction of a source of measurement error. Incomes for top-coded values are imputed by multiplying the top code value $(\$ 175,000)$ by $1.5 .^{59}$

In equation (15), vector $Z_{k i}$ includes indicators for 4 categories of educational attainment, ${ }^{60}$ a quartic polynomial in age, race and gender dummies (plus their interaction), Hispanic and immigrant dummies (plus their interaction) and state of residence dummies. Residual wages are constructed as $\widehat{\xi_{k i}}=\log \left(w_{k i}\right)-Z_{k i} \widehat{\beta}_{i}$, where $\widehat{\beta}_{i}$ is estimated by OLS.

Correcting for self-selection into industries is important in estimating equation (15), as the assumption that workers do not selectively search for jobs according to comparative advantage or unobservable tastes is relevant for Proposition 6. In the presence of self-selection the distribution

\footnotetext{
${ }^{57}$ These results are available upon request.

${ }^{58}$ Manufacturing employment excludes workers in private non-profit and government organizations.

${ }^{59}$ Since top codes vary by state, we follow Beaudry et al. (2007) and impose a common top-code value of $\$ 175,000$.

${ }^{60}$ These are: (i) High school dropout, (ii) high school graduate, (iii) some college but no degree, (iv) college degree or higher.
} 
of residual wages in any given industry would reflect not only the degree of skill substitutability in production but also workers' skill composition. For this reason, we use a selection estimator proposed by Dahl (2002). In equation (15), correcting for self-selection is complicated by the fact that individuals could choose to search for a job in any of the 63 industries of the manufacturing sector, potentially making the error mean, i.e. $E\left(\xi_{k i} \mid k\right.$ is observed in $\left.i\right)$, a function of the characteristics of all the alternatives. In this case, Dahl (2002) argues that under a specific sufficiency assumption, ${ }^{61}$ the error mean is only a function of the probability that a person born in the same state as $k$ would make the choice that $k$ actually made (i.e. selecting into industry $i$ ), which can be estimated. The sufficiency assumption can be relaxed by including functions of additional selection probabilities; for this reason, $Z_{k i}$ includes a cubic polynomial in the estimated first-best selection probability and in the highest predicted probability for $k$. Identification in this approach is based on the exclusion of state of birth by industry of employment interactions from equation (15).

To estimate selection probabilities, we group individuals into cells defined by state of birth ${ }^{62}$ and a vector of discrete characteristics: 4 categories of education attainment, 4 age intervals (1630, 31-40, 41-50, 51-65), race, gender and 2 binary indicators of family status (family/non-family household and presence of own child 18 or younger in the household). As in Dahl (2002), for every individual $k$, we estimate his selection probability into each industry $j$ using the proportion of individuals within $k$ 's cell that are observed working in $j$, denoted by $\widehat{p_{k j}}$. Individual $k$ 's estimated first-best selection probability is $\widehat{p_{k i}}$ and $k$ 's highest predicted probability is given by $\widehat{p_{k j_{*}}}$, where $j_{*}$ is such that $\widehat{p_{k j_{*}}}=\max \left\{\widehat{p_{k j}}\right\} \forall j$.

For the empirical analysis, the Census industry classification was matched to NAICS. It was not possible to match the trade data to Census codes directly, since the former is originally coded according to the Standard International Trade Classification (SITC rev.2). However, it is possible to use NAICS as a bridge between the two classifications. We construct a one-to-one mapping between the Census classification and NAICS by re-coding two or more 4 digit NAICS codes into a single industry (which does not necessarily match a 3 digit level). This re-coding also involves cases where two Census codes map perfectly into two NAICS codes -although originally there was no one-to-one matching between them. Importantly, the resulting mapping (available upon request) exhausts all manufacturing sectors in NAICS. Finally, the trade data was matched to wage inequality data using a concordance between SITC rev. 2 and NAICS, available through the NBER online database.

\section{Appendix - Additional Data}

In this Appendix we provide a description of additional data sources used in the empirical analysis. Descriptive statistics for each variable can be found in table 8 .

Bilateral export volumes at the industry level: From Feenstra et al. (2005), for the year 2000. Sector-level bilateral exports data are categorized at the 4-digit SITC (4-digit rev. 2) level. The mapping from SITC to NAICS required the concordance available at the NBER website. ${ }^{63}$

Bilateral trade barriers: From HMR. This is a set of exporter-importer specific geographical, cultural and institutional variables. 1) Distance, the distance (in km.) between importer's and exporter's capitals (in logs). 2) Land border, a binary variable that equals one if and only if

\footnotetext{
${ }^{61}$ See Dahl (2002), page 2378.

${ }^{62}$ As in Beaudry et al. (2007), we keep immigrants in the analysis by dividing the rest of the world into 14 regions (or 'states' of birth).

${ }^{63}$ http://www.nber.org/lipsey/sitc22naics97/
} 
importer and exporter are neighbors that meet a common physical boundary. 3) Island, the number of countries in the pair that are islands. 4) Landlocked, the number of countries in the pair that have no coastline or direct access to sea. 5) Colonial ties, a binary variable that equals one if and only if the importing country ever colonized the exporting country or vice versa. 6) Legal system, a binary variable that equals one if and only if the importing and exporting countries share the same legal origin. 7) Common Language, a binary variable that equals one if and only if the exporting importing countries share a common language. 8) Religion, computed as (\% Protestants in exporter $\times \%$ Protestants in importer $)+(\%$ Catholics in exporter $\times \%$ Catholics in importer $)+(\%$ Muslims in exporter $\times \%$ Muslims in importer). 9) FTA, a binary variable that equals one if exporting and importing countries belong to a common regional trade agreement, and zero otherwise. 10) GATT/WTO, the number of countries in the pair that belong to the GATT/WTO.

Start-up regulation costs: From HMR. We use exporter-importer interactions of three proxies of regulation costs: the number of days $\left(\operatorname{RegDays}_{H} \times \operatorname{RegDays}_{F}\right)$, number of legal procedures $\left(\operatorname{RegProc}_{H} \times \operatorname{RegProc}_{F}\right)$ and relative cost as a percentage of GDP per capita $\left(\operatorname{RegProc}_{H} \times\right.$ $\left.\operatorname{RegProc}_{F}\right)$, for an entrepreneur to start operating a business.

Factor endowments: Physical capital endowment, KEndow, and human capital endowment, SkillEndow, are taken from Antweiler and Trefler (2002). A country's stock of physical capital is the $\log$ of the average capital stock per worker. The stock of human capital is the natural $\log$ of the ratio of workers that completed high school to those that did not. The measures used are from 1992, the closest year of which data are available. There's no data on factor endowments for four countries in our sample: Switzerland, Czech Republic, Hungary and Poland.

Factor intensities: From Nunn (2007). Originally coded as 1997 I-O industries, the mapping to NAICS required a concordance available from the Bureau of Economic Analysis. ${ }^{64}$ Physical capital intensity, KIntens, is the total real capital stock divided by value added of the industry in the United States in 1996. Skill intensity, SkillIntens, is the ratio of non-production worker wages to total wages at the industry level in the United States in 1996. There's no data on factor intensities for two industries: 'Furniture and related products manufacturing' and 'Sawmills and wood preservation'.

Proportion of top-coded wages: From the 2000 Census of Population in the U.S. For each industry, TopCode is calculated as the proportion of workers earning a wage exceeding the top code value of $\$ 175,000$.

Firm size dispersion: From the 1997 Census of manufacturing in the U.S. For each industry, we calculate FirmDisp, the coefficient of variation in the average shipments per establishment across bins defined by employment size. The employment bins defined in the Census are: 1-4, 5-9, 10-19, 20-49, 50-99, 100-249, 250-499, 500-999, 1000-2499 and 2500 employees or more.

\footnotetext{
${ }^{64}$ http://www.bea.gov/industry/xls/1997import_matrix.xls
} 


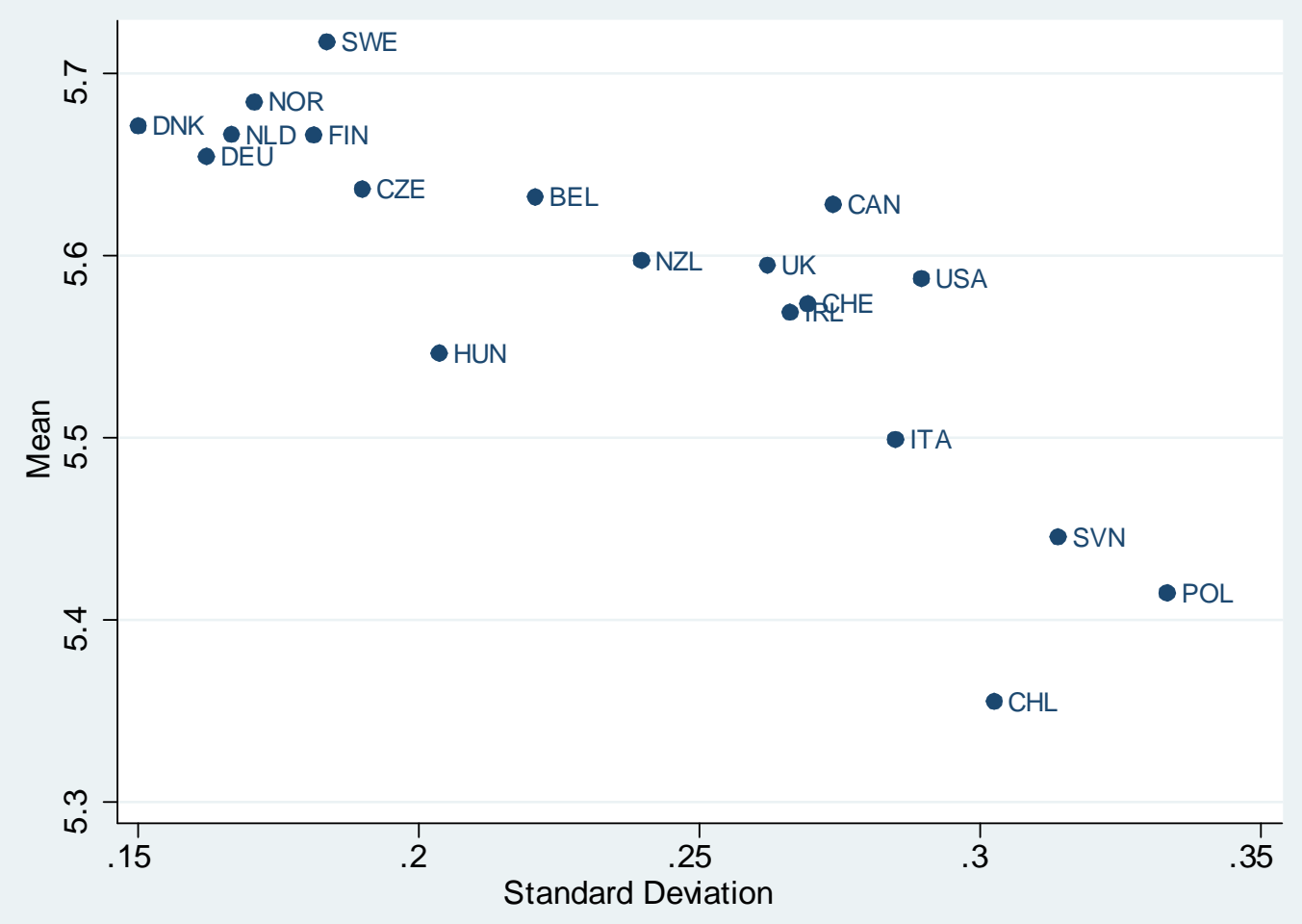

Figure 1: Mean and Dispersion in IALS log-scores (1994-1998)

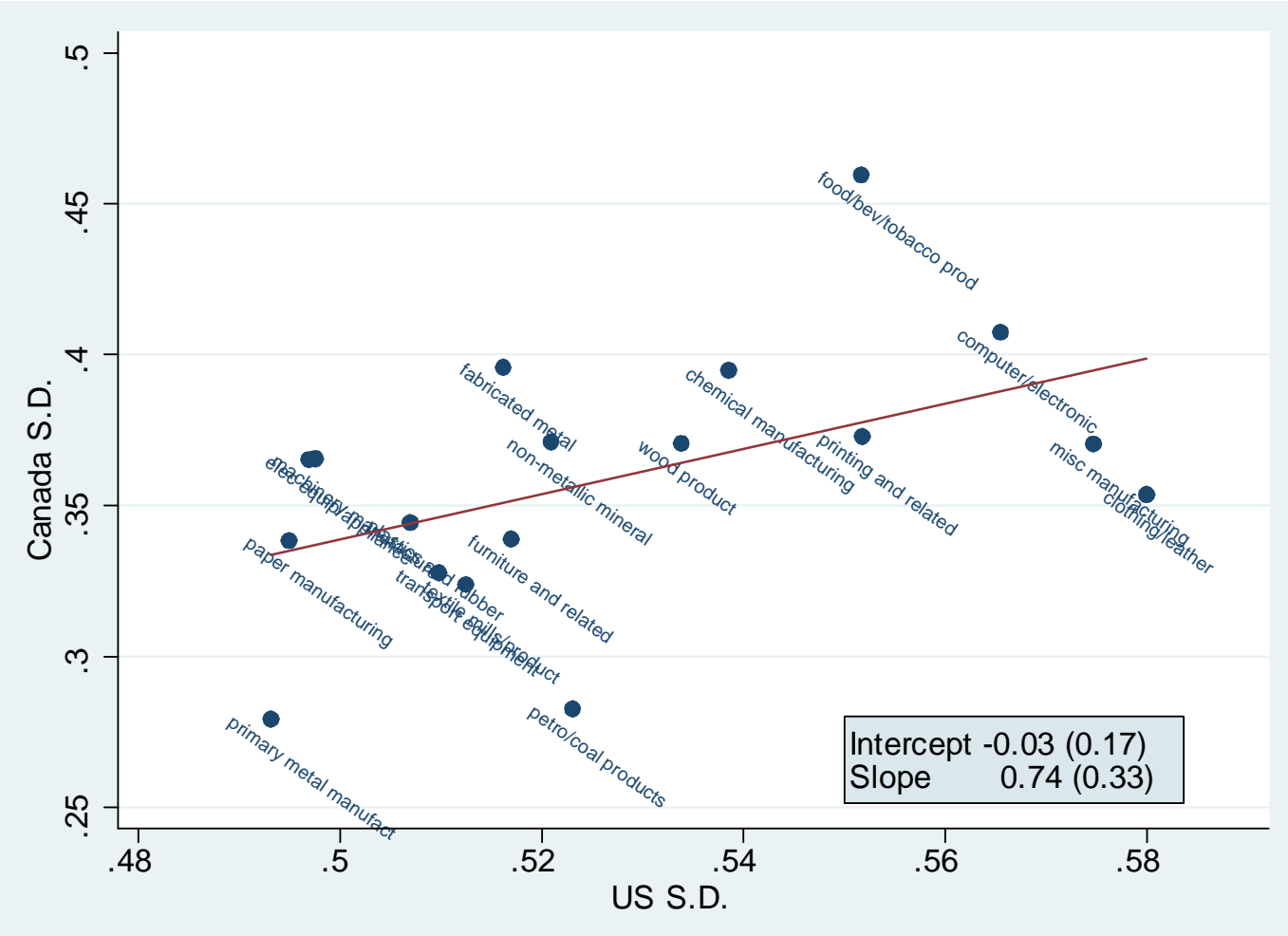

Figure 2: Standard Deviation of Residual Wages by Industry 
Table 1 - IALS log-scores

\begin{tabular}{ll|ll|ll|ll}
\hline \multirow{2}{*}{ CV Rank } & Exporter & \multicolumn{2}{|c|}{ Mean } & \multicolumn{2}{c|}{ St Dev } & \multicolumn{2}{l}{ St Dev Resid } \\
& & & & & \\
Rank & \\
& & & & & & \\
\hline 1 & Denmark & 3 & 5.671 & 1 & 0.150 & 1 & 0.134 \\
2 & Germany & 6 & 5.654 & 2 & 0.162 & 3 & 0.151 \\
3 & Netherlands & 4 & 5.666 & 3 & 0.167 & 2 & 0.149 \\
4 & Norway & 2 & 5.684 & 4 & 0.171 & 4 & 0.156 \\
5 & Finland & 5 & 5.666 & 5 & 0.181 & 5 & 0.162 \\
6 & Sweden & 1 & 5.717 & 6 & 0.184 & 6 & 0.168 \\
7 & Czech Republic & 7 & 5.636 & 7 & 0.190 & 7 & 0.171 \\
8 & Hungary & 15 & 5.546 & 8 & 0.204 & 9 & 0.192 \\
9 & Belgium & 8 & 5.632 & 9 & 0.221 & 10 & 0.199 \\
10 & New Zeland & 10 & 5.597 & 10 & 0.240 & 13 & 0.222 \\
11 & United Kingdom & 11 & 5.595 & 11 & 0.262 & 19 & 0.318 \\
12 & Ireland & 14 & 5.569 & 12 & 0.266 & 12 & 0.222 \\
13 & Switzerland & 13 & 5.573 & 13 & 0.269 & 8 & 0.189 \\
14 & Canada & 9 & 5.628 & 14 & 0.274 & 11 & 0.216 \\
15 & Italy & 16 & 5.499 & 15 & 0.285 & 16 & 0.256 \\
16 & United States & 12 & 5.587 & 16 & 0.289 & 14 & 0.227 \\
17 & Chile & 19 & 5.355 & 17 & 0.302 & 15 & 0.230 \\
18 & Slovenia & 17 & 5.446 & 18 & 0.314 & 17 & 0.260 \\
19 & Poland & 18 & 5.415 & 19 & 0.333 & 18 & 0.312 \\
\hline \hline
\end{tabular}


Table 2 - Wage Dispersion

\begin{tabular}{|c|c|c|c|c|c|c|c|}
\hline \multirow{2}{*}{$\begin{array}{l}\mathrm{CV} \\
\text { Rank } \\
1\end{array}$} & \multirow{2}{*}{$\begin{array}{l}\text { Exporter } \\
\text { Railroad rolling stock }\end{array}$} & \multicolumn{2}{|c|}{$\begin{array}{l}\text { Mean } \\
\text { Log Wage } \\
\text { Rank }\end{array}$} & \multicolumn{2}{|c|}{$\begin{array}{l}\text { St Dev } \\
\text { Log Wage } \\
\text { Rank }\end{array}$} & \multicolumn{2}{|c|}{$\begin{array}{l}\text { St Dev Res } \\
\text { Log Wage } \\
\text { Rank }\end{array}$} \\
\hline & & 22 & 6.504 & 1 & 0.515 & 1 & 0.419 \\
\hline 2 & Aircraft, aerospace products and parts & 4 & 6.814 & 6 & 0.560 & 7 & 0.462 \\
\hline 3 & Nonferrous metals, exc. aluminum & 25 & 6.485 & 3 & 0.544 & 2 & 0.442 \\
\hline 4 & Fiber, yarn, and thread mills & 56 & 6.153 & 2 & 0.521 & 3 & 0.448 \\
\hline 5 & Pulp, paper, and paperboard mills & 9 & 6.654 & 8 & 0.564 & 9 & 0.473 \\
\hline 6 & Engines, turbines, and power trans. equipment & 10 & 6.620 & 10 & 0.570 & 4 & 0.455 \\
\hline 7 & Dairy products & 38 & 6.377 & 5 & 0.552 & 6 & 0.461 \\
\hline 8 & Veneer, plywood, and engineered wood products & 45 & 6.291 & 4 & 0.547 & 11 & 0.477 \\
\hline 9 & Iron and steel mills and steel product & 15 & 6.583 & 13 & 0.573 & 16 & 0.490 \\
\hline 10 & Ship and boat building & 30 & 6.443 & 7 & 0.564 & 8 & 0.467 \\
\hline 11 & Cement, concrete, lime, and gypsum & 28 & 6.455 & 11 & 0.571 & 20 & 0.492 \\
\hline 12 & Foundries & 35 & 6.391 & 9 & 0.565 & 13 & 0.485 \\
\hline 13 & Industrial and miscellaneous chemicals & 5 & 6.784 & 30 & 0.608 & 25 & 0.497 \\
\hline 14 & Aluminum production and processing & 21 & 6.511 & 17 & 0.587 & 12 & 0.485 \\
\hline 15 & Rubber products & 29 & 6.454 & 15 & 0.584 & 15 & 0.488 \\
\hline 16 & Agric implement, constr., mining and oil field machinery & 18 & 6.525 & 23 & 0.596 & 10 & 0.474 \\
\hline 17 & Household appliances & 44 & 6.339 & 14 & 0.579 & 5 & 0.461 \\
\hline 18 & Metalworking machinery & 20 & 6.513 & 22 & 0.595 & 23 & 0.496 \\
\hline 19 & Machinery, n.e.c. & 26 & 6.471 & 24 & 0.598 & 18 & 0.491 \\
\hline 20 & Structural metals, and tank and shipping containers & 37 & 6.380 & 18 & 0.589 & 33 & 0.507 \\
\hline 21 & Machine shops; turned product; screw, nut and bolt mfg. & 32 & 6.400 & 19 & 0.591 & 44 & 0.523 \\
\hline 22 & Ordinance and misc. fabricated metal & 39 & 6.376 & 20 & 0.592 & 19 & 0.491 \\
\hline 23 & Petroleum and Coal Products & 1 & 6.835 & 39 & 0.636 & 42 & 0.519 \\
\hline 24 & Paperboard containers, boxes misc. paper and pulp & 31 & 6.414 & 27 & 0.604 & 22 & 0.496 \\
\hline 25 & Glass & 42 & 6.355 & 26 & 0.601 & 34 & 0.507 \\
\hline 26 & Animal slaughtering and processing & 61 & 6.051 & 12 & 0.572 & 26 & 0.498 \\
\hline 27 & Furniture & 54 & 6.169 & 16 & 0.586 & 36 & 0.510 \\
\hline 28 & Navig, measuring, electromedical, and control instr. & 8 & 6.666 & 37 & 0.634 & 21 & 0.495 \\
\hline 29 & Resin, synthetic rubber and fibers, and filaments & 14 & 6.591 & 35 & 0.628 & 17 & 0.490 \\
\hline 30 & Cutlery and hand tools & 41 & 6.364 & 29 & 0.607 & 14 & 0.486 \\
\hline 31 & Sawmills and wood preservation & 51 & 6.206 & 21 & 0.595 & 37 & 0.511 \\
\hline 32 & Animal food, grain and oilseed milling & 27 & 6.470 & 34 & 0.624 & 38 & 0.513 \\
\hline
\end{tabular}


Table 2 - Continued

\begin{tabular}{|c|c|c|c|c|c|c|c|}
\hline \multirow[b]{2}{*}{33} & \multirow[b]{2}{*}{ Miscellaneous nonmetallic minerals } & \multicolumn{2}{|c|}{$\begin{array}{l}\text { Mean } \\
\text { Log Wage } \\
\text { Rank }\end{array}$} & \multicolumn{2}{|c|}{$\begin{array}{l}\text { St Dev } \\
\text { Log Wage } \\
\text { Rank }\end{array}$} & \multicolumn{2}{|c|}{$\begin{array}{l}\text { St Dev Res } \\
\text { Log Wage } \\
\text { Rank }\end{array}$} \\
\hline & & 36 & 6.382 & 33 & 0.621 & 39 & 0.514 \\
\hline 34 & Commercial and service industry machinery & 12 & 6.613 & 44 & 0.646 & 24 & 0.497 \\
\hline 35 & Beverages & 17 & 6.537 & 43 & 0.641 & 45 & 0.532 \\
\hline 36 & Fabric Mills & 57 & 6.123 & 25 & 0.601 & 29 & 0.502 \\
\hline 37 & Motor vehicles and motor vehicle equipment & 13 & 6.594 & 45 & 0.648 & 43 & 0.521 \\
\hline 38 & Electrical lighting, equipment, and supplies, n.e.c. & 33 & 6.399 & 36 & 0.631 & 27 & 0.500 \\
\hline 39 & Plastics & 47 & 6.271 & 32 & 0.619 & 31 & 0.504 \\
\hline 40 & Textile product mills & 59 & 6.089 & 28 & 0.605 & 35 & 0.509 \\
\hline 41 & Prefab. wood build., mobile homes and misc. wood prod & 53 & 6.190 & 31 & 0.617 & 48 & 0.542 \\
\hline 42 & Agricultural chemicals & 16 & 6.579 & 47 & 0.657 & 40 & 0.518 \\
\hline 43 & Paint, coating, and adhesive B46 & 19 & 6.523 & 46 & 0.652 & 46 & 0.534 \\
\hline 44 & Printing and related support activities & 40 & 6.370 & 42 & 0.639 & 49 & 0.546 \\
\hline 45 & Pharmaceutical and medicine & 3 & 6.821 & 56 & 0.694 & 50 & 0.550 \\
\hline 46 & Pottery, ceramics and structural clay & 48 & 6.262 & 40 & 0.637 & 47 & 0.541 \\
\hline 47 & Fruit and vegetable preserving and specialty food & 49 & 6.239 & 38 & 0.635 & 41 & 0.518 \\
\hline 48 & Other transportation equipment & 34 & 6.394 & 48 & 0.658 & 30 & 0.503 \\
\hline 49 & Textile and fabric finishing and coating mills & 52 & 6.197 & 41 & 0.637 & 32 & 0.504 \\
\hline 50 & Tobacco & 6 & 6.728 & 57 & 0.705 & 55 & 0.558 \\
\hline 51 & Footwear & 58 & 6.116 & 49 & 0.659 & 28 & 0.500 \\
\hline 52 & Toys, amusement, sporting goods and misc, n.e.c. & 50 & 6.234 & 52 & 0.672 & 61 & 0.565 \\
\hline 53 & Communications, audio, and video equipment & 7 & 6.724 & 60 & 0.725 & 59 & 0.562 \\
\hline 54 & Computer and peripheral equipment & 2 & 6.834 & 62 & 0.739 & 62 & 0.576 \\
\hline 55 & Medical equipment and supplies & 24 & 6.496 & 58 & 0.706 & 53 & 0.553 \\
\hline 56 & Bakeries & 55 & 6.166 & 51 & 0.670 & 63 & 0.576 \\
\hline 57 & Sugar and confectionery products & 46 & 6.285 & 54 & 0.683 & 51 & 0.550 \\
\hline 58 & Leather tanning and products, except footwear & 60 & 6.069 & 50 & 0.667 & 54 & 0.556 \\
\hline 59 & Electronic component and product, n.e.c. & 11 & 6.620 & 61 & 0.730 & 57 & 0.559 \\
\hline 60 & Seafood and other miscellaneous foods, n.e.c. & 43 & 6.346 & 59 & 0.712 & 52 & 0.551 \\
\hline 61 & Cut and sew apparel & 63 & 5.876 & 53 & 0.677 & 60 & 0.564 \\
\hline 62 & Soap, cleaning compound, and cosmetics & 23 & 6.503 & 63 & 0.754 & 56 & 0.559 \\
\hline 63 & Apparel accessories and other apparel & 62 & 5.900 & 55 & 0.689 & 58 & 0.560 \\
\hline
\end{tabular}


Table 3 - Normalized Raw Scores and Wages

Measure

of Dispersion
(1)

$\frac{\text { St Dev }}{\text { Mean }} \quad \frac{95-5 \text { IPR }}{\text { Mean }}$
(3)

Gini RMD
(4)

(5)
(6)

Gini RMD

\begin{tabular}{lcccccc}
\hline & & & & & & \\
WageDisp & $\times$ SkillDisp & & \\
& $0.168^{* *}$ & $0.107^{*}$ & $0.121^{* *}$ & $0.193^{* *}$ & $0.122^{* *}$ & $0.122^{* *}$ \\
& $(0.048)$ & $(0.046)$ & $(0.047)$ & $(0.046)$ & $(0.046)$ & $(0.046)$ \\
\hline Trade Barriers & No & No & No & Yes & Yes & Yes \\
Exporter FE & Yes & Yes & Yes & Yes & Yes & Yes \\
Importer FE & Yes & Yes & Yes & No & No & No \\
Industry FE & Yes & Yes & Yes & No & No & No \\
Importer-Industry FE & No & No & No & Yes & Yes & Yes \\
& & & & & & 58124 \\
Observations & 58124 & 58124 & 58124 & 58124 & 58124 & 0.7 \\
R-squared & 0.54 & 0.54 & 0.54 & 0.7 & 0.69 & \\
\end{tabular}

The dependent variable is the natural logarithm of exports from country $H$ to country $F$ in industry $i$.

Standardized beta coefficients are reported. ${ }^{\dagger},{ }^{*}$ and $* *$ indicate the coefficient is significant at the $10 \%, 5 \%$ and $1 \%$ levels. Standard errors clustered by importer-exporter pair in parenthesis. 
Table 4 - Non-Normalized Interactions

Measure of

Dispersion
(1)

(2)

St Dev 95-5 IPR Gini MD
(3)
(4)
(5)
(6)

Dispersion

\begin{tabular}{|c|c|c|c|c|c|c|}
\hline WageDisp $_{i} \times$ SkillDisp $_{H}$ & $\begin{array}{c}0.210^{* *} \\
(0.079)\end{array}$ & $\begin{array}{l}0.076 \\
(0.074)\end{array}$ & $\begin{array}{l}0.208^{*} \\
(0.091)\end{array}$ & $\begin{array}{c}0.331^{* *} \\
(0.076)\end{array}$ & $\begin{array}{r}0.176^{* *} \\
(0.067)\end{array}$ & $\begin{array}{r}0.330^{* *} \\
(0.085)\end{array}$ \\
\hline WageMean $_{i} \times$ SkillMean $_{H}$ & $\begin{array}{c}9.132^{* *} \\
(0.602)\end{array}$ & $\begin{array}{c}10.232^{* *} \\
(0.590)\end{array}$ & $\begin{array}{c}10.696^{* *} \\
(0.708)\end{array}$ & $\begin{array}{c}9.626^{* *} \\
(0.504)\end{array}$ & $\begin{array}{c}10.561^{* *} \\
(0.503)\end{array}$ & $\begin{array}{r}10.853^{* *} \\
(0.595)\end{array}$ \\
\hline WageMean $_{i} \times$ SkillDisp $_{H}$ & $\begin{array}{c}2.396^{* *} \\
(0.240)\end{array}$ & $\begin{array}{c}2.972^{* *} \\
(0.232)\end{array}$ & $\begin{array}{r}3.050^{* *} \\
(0.285)\end{array}$ & $\begin{array}{c}2.233^{* *} \\
(0.197)\end{array}$ & $\begin{array}{r}2.726^{* *} \\
(0.195)\end{array}$ & $\begin{array}{r}2.749 * * \\
(0.238)\end{array}$ \\
\hline WageDisp $_{i} \times$ SkillMean $_{H}$ & $\begin{array}{l}0.777 \\
(0.487)\end{array}$ & $\begin{array}{l}0.098 \\
\quad(0.481)\end{array}$ & $\begin{array}{l}1.039 \\
(0.568)\end{array}$ & $\begin{array}{c}1.669^{* *} \\
(0.485)\end{array}$ & $\begin{array}{l}0.900^{\dagger} \\
(0.461)\end{array}$ & $\begin{array}{r}2.014^{* *} \\
(0.550)\end{array}$ \\
\hline Trade Barriers & No & No & No & Yes & Yes & Yes \\
\hline Exporter FE & Yes & Yes & Yes & Yes & Yes & Yes \\
\hline Importer FE & Yes & Yes & Yes & No & No & No \\
\hline Industry FE & Yes & Yes & Yes & No & No & No \\
\hline Importer-Industry FE & No & No & No & Yes & Yes & Yes \\
\hline Observations & 58124 & 58124 & 58124 & 58124 & 58124 & 58124 \\
\hline R-squared & 0.54 & 0.54 & 0.54 & 0.70 & 0.70 & 0.70 \\
\hline
\end{tabular}

The dependent variable is the natural logarithm of exports from country $H$ to country $F$ in industry $i$. Standardized beta coefficients are reported. ${ }^{\dagger},{ }^{*}$ and ${ }^{* *}$ indicate the coefficient is significant at the $10 \%, 5 \%$ and $1 \%$ levels. Standard errors clustered by importer-exporter pair in parenthesis. 
Table 5 - Residual Wage and Residual Score Dispersion
(1)
$(2)$
$(3)$
$(4)$
$(5)$
$(6)$

Measure of

Dispersion

St Dev 95-5 IPR Gini MD St Dev 95-5 IPR Gini MD

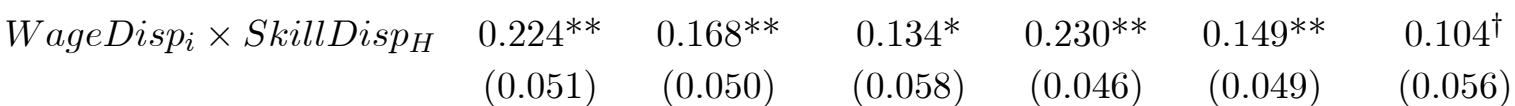

$\begin{array}{lcccccc}\text { Trade Barriers } & \text { No } & \text { No } & \text { No } & \text { Yes } & \text { Yes } & \text { Yes } \\ \text { Exporter FE } & & & & & & \\ \text { Importer FE } & \text { Yes } & \text { Yes } & \text { Yes } & \text { Yes } & \text { Yes } & \text { Yes } \\ \text { Industry FE } & \text { Yes } & \text { Yes } & \text { Yes } & \text { No } & \text { No } & \text { No } \\ \text { Importer-Industry FE } & \text { No } & \text { No } & \text { No } & \text { Yes } & \text { Yes } & \text { No } \\ & & & & & & \\ \text { Observations } & 58124 & 58124 & 58124 & 58124 & 58124 & 58124 \\ \text { R-squared } & 0.54 & 0.54 & 0.54 & 0.70 & 0.70 & 0.69\end{array}$

The dependent variable is the natural logarithm of exports from country $H$ to country $F$ in industry $i$. Standardized beta coefficients are reported. ${ }^{\dagger},{ }^{*}$ and ${ }^{* *}$ indicate the coefficient is significant at the $10 \%, 5 \%$ and $1 \%$ levels. Bootstrap standard errors clustered by importerexporter pair in parenthesis (50 replications). 
Table 6 - Selection and Other Controls

WageDisp ${ }_{i} \times$ SkillDisp $_{H}$
KIntens $_{i} \times$ KEndow $_{H}$
SkillIntens $_{i} \times$ SkillEndow $_{H}$
FirmDisp $_{i} \times$ SkillDisp $_{H}$
TopCode $_{i} \times$ SkillDisp $_{H}$

(1)

(2)

Baseline
$0.230^{* *}$

(0.046)

$0.212^{* *}$

$0.306^{* *}$

$0.229 * *$

$0.377^{* *}$

$0.210^{* *}$

(0.049)

(0.063)

$0.250^{* *}$

(0.059)

(0.075)

(0.044)

(0.074)

$0.122^{* *}$

(0.018)

$-0.010$

(0.023)

$-0.087^{*}$

$(0.034)$

\begin{tabular}{lcccccc}
\hline Trade Barriers & Yes & Yes & Yes & Yes & Yes & Yes \\
Exporter FE & Yes & Yes & Yes & Yes & Yes & Yes \\
Importer-Industry FE & Yes & Yes & Yes & Yes & Yes & Yes \\
& & & & & & \\
Observations & 58124 & 52455 & 41301 & 52455 & 52455 & 48129 \\
R-squared & 0.69 & 0.69 & 0.73 & 0.69 & 0.69 & 0.68 \\
& & & & & & \\
\hline \hline
\end{tabular}

The dependent variable is the natural logarithm of exports from country $H$ to country $F$ in industry $i$. Standardized beta coefficients are reported. ${ }^{\dagger},{ }^{*}$ and $* *$ indicate the coefficient is significant at the $10 \%, 5 \%$ and $1 \%$ levels. Bootstrap standard errors clustered by importer-exporter pair in parenthesis (50. replications). The measure of dispersion employed is the standard deviation of residual wages and residual scores. Column (6) is the same specification of column (2) excluding the observations involving US as exporter. The regression includes a polynomial in the probability to export, obtained from the first stage, which is significant and we do not report. 
Table 7 - First Stages of Table 6

\begin{tabular}{|c|c|c|c|c|c|}
\hline & (1) & $(2)$ & $(3)$ & (4) & $(5)$ \\
\hline & $\begin{array}{c}\text { HMR } \\
\text { Selection }\end{array}$ & $\begin{array}{c}\text { Heckscher } \\
\text { Ohlin }\end{array}$ & $\begin{array}{l}\text { Firm Size } \\
\text { Dispersion }\end{array}$ & $\begin{array}{c}\text { Top } \\
\text { Coding }\end{array}$ & $\begin{array}{c}\text { Without } \\
\text { US }\end{array}$ \\
\hline WageDisp $_{i} \times$ SkillDisp $_{H}$ & $\begin{array}{l}0.025^{\dagger} \\
(0.014)\end{array}$ & $\begin{array}{c}0.090^{* *} \\
(0.016)\end{array}$ & $\begin{array}{c}0.063^{* *} \\
(0.015)\end{array}$ & $\begin{array}{c}0.118^{* *} \\
(0.017)\end{array}$ & $\begin{array}{l}0.024^{\dagger} \\
(0.014)\end{array}$ \\
\hline $\operatorname{RegCosts}_{H} \times \operatorname{RegCosts}_{F}$ & $\begin{array}{c}0.013^{* *} \\
(0.004)\end{array}$ & $\begin{array}{c}0.001 \\
(0.006)\end{array}$ & $\begin{array}{c}0.013^{* *} \\
(0.004)\end{array}$ & $\begin{array}{c}0.013^{* *} \\
(0.004)\end{array}$ & $\begin{array}{c}0.006 \\
(0.003)\end{array}$ \\
\hline $\operatorname{RegDays}_{H} \times \operatorname{RegDays}_{F}$ & $\begin{array}{l}0.014^{*} \\
(0.006)\end{array}$ & $\begin{array}{c}0.020 \\
(0.012)\end{array}$ & $\begin{array}{c}0.014^{*} \\
(0.006)\end{array}$ & $\begin{array}{l}0.014^{*} \\
(0.006)\end{array}$ & $\begin{array}{l}0.012^{*} \\
(0.005)\end{array}$ \\
\hline $\operatorname{RegProc}_{H} \times \operatorname{RegProc}_{F}$ & $\begin{array}{c}0.029^{* *} \\
(0.009)\end{array}$ & $\begin{array}{c}0.077^{* *} \\
(0.018)\end{array}$ & $\begin{array}{c}0.029 * * \\
(0.009)\end{array}$ & $\begin{array}{c}0.029 * * \\
(0.009)\end{array}$ & $\begin{array}{c}0.031^{* *} \\
(0.011)\end{array}$ \\
\hline KIntens $_{i} \times$ KEndow $_{H}$ & & $\begin{array}{l}0.027^{*} \\
(0.012)\end{array}$ & & & \\
\hline SkillIntens $_{i} \times$ SkillEndow $_{H}$ & & $\begin{array}{c}-0.013^{*} \\
(0.005)\end{array}$ & & & \\
\hline FirmDisp $_{i} \times$ SkillDisp $_{H}$ & & & $\begin{array}{c}-0.035^{* *} \\
(0.005)\end{array}$ & & \\
\hline TopCode $_{i} \times$ SkillDisp $_{H}$ & & & & $\begin{array}{c}-0.055^{* *} \\
(0.008)\end{array}$ & \\
\hline Trade Barriers & Yes & Yes & Yes & Yes & Yes \\
\hline Exporter FE & Yes & Yes & Yes & Yes & Yes \\
\hline Importer-Industry FE & Yes & Yes & Yes & Yes & Yes \\
\hline Observations & 132867 & 94794 & 132867 & 132867 & 124740 \\
\hline R-squared & 0.57 & 0.59 & 0.58 & 0.58 & 0.58 \\
\hline
\end{tabular}

Columns (1)-(5) report the first stage estimation results corresponding to Columns (2)-(6) of Table D. The dependent variable is a dummy that is one if exports from country $H$ to country $F$ in industry $i$ are positive and zero otherwise. Standardized beta coefficients are reported. $\dagger, *$ and ${ }^{* *}$ indicate the coefficient is significant at the $10 \%, 5 \%$ and $1 \%$ levels. Bootstrap standard errors clustered by importer-exporter pair in parenthesis (50 replications). The measure of dispersion employed is the standard deviation of residual wages and residual scores. Column (6) is the same specification of column (2) excluding the observations involving US as exporter. All estimations were performed with a linear probability model. 


\begin{tabular}{|c|c|c|c|c|c|}
\hline \multicolumn{6}{|c|}{ Table 8 - Additional Variables } \\
\hline Variable & Obs & Mean & Std. Dev & Min & Max \\
\hline Exports dummy & 173565 & 0.335 & 0.472 & 0 & 1 \\
\hline Exports volume $\left(X_{H F i}\right)$ & 58124 & 7.866 & 2.204 & 0 & 17.906 \\
\hline Language & 2755 & 0.193 & 0.395 & 0 & 1 \\
\hline Legal & 2755 & 0.217 & 0.412 & 0 & 1 \\
\hline Religion & 2755 & 0.196 & 0.257 & 0 & 0.973 \\
\hline Land Border & 2755 & 0.019 & 0.135 & 0 & 1 \\
\hline Currency Union & 2755 & 0.002 & 0.047 & 0 & 1 \\
\hline Distance & 2755 & 4.136 & 0.806 & 0.882 & 5.661 \\
\hline FTA & 2755 & 0.017 & 0.131 & 0 & 1 \\
\hline Colonial Ties & 2755 & 0.022 & 0.146 & 0 & 1 \\
\hline Gatt / WTO & 2755 & 1.489 & 0.578 & 0 & 2 \\
\hline Island & 2755 & 0.291 & 0.494 & 0 & 2 \\
\hline Landlock & 2755 & 0.309 & 0.509 & 0 & 2 \\
\hline $\operatorname{RegProc}_{F}$ & 112 & 9.679 & 3.491 & 2 & 19 \\
\hline $\operatorname{RegDays}_{F}$ & 112 & 49.402 & 38.593 & 2 & 203 \\
\hline RegCosts $_{F}$ & 112 & 90.065 & 165.785 & 0 & 1268.4 \\
\hline $\operatorname{RegProc}_{H}$ & 19 & 5.947 & 2.818 & 2 & 10 \\
\hline $\operatorname{RegDays}_{H}$ & 19 & 23.842 & 16.433 & 3 & 61 \\
\hline $\operatorname{RegCosts}_{H}$ & 19 & 7.874 & 7.190 & 0 & 22.9 \\
\hline SkillEndow $_{H}$ & 14 & -3.435 & 0.402 & -4.522 & -2.957 \\
\hline KEndow $_{H}$ & 14 & -0.530 & 0.662 & -1.377 & 0.925 \\
\hline SkillIntens $_{i}$ & 61 & 0.381 & 0.116 & 0.166 & 0.757 \\
\hline KIntens $_{i}$ & 61 & 0.859 & 0.464 & 0.235 & 2.535 \\
\hline TopCode $_{i}$ & 63 & 0.009 & 0.005 & 0.004 & 0.030 \\
\hline FirmDisp $_{i}$ & 63 & 3.055 & 1.418 & 1.015 & 6.940 \\
\hline
\end{tabular}




\section{References}

Acemoglu, D., Antràs, P., Helpman, E., 2007. Contracts and technology adoption. American Economic Review 97 (3), 916-943.

Adda, J., Dustmann, C., Meghir, C., Robin, J., Street, G., 2006. Career progression and formal versus on-the-job training. IZA Discussion Paper 2260.

Antweiler, W., Trefler, D., 2002. Increasing returns and all that: a view from trade. American Economic Review, 93-119.

Aumann, R. J., Shapley, L. S., 1974. Values of non-atomic games. Princeton University Press Princeton.

Beaudry, P., Green, D., Sand, B., 2007. Spill-Overs from Good Jobs. NBER working paper 13006.

Behrens, K., Lamorgese, A., Ottaviano, G., Tabuchi, T., 2009. Beyond the Home Market Effect: Market Size and Specialization in a Multi-Country World. Mimeo, University of Tokyo.

Benabou, R., 1996. Heterogeneity, stratification, and growth: macroeconomic implications of community structure and school finance. The American Economic Review, 584-609.

Bernard, A., Jensen, J., 1997. Exporters, skill upgrading, and the wage gap. Journal of International Economics 42 (1-2), 3-31.

Bernard, A., Jensen, J., Lawrence, R., 1995. Exporters, jobs, and wages in US manufacturing: 1976-1987. Brookings Papers on Economic Activity. Microeconomics, 67-119.

Bougheas, S., Riezman, R., 2007. Trade and the distribution of human capital. Journal of International Economics 73 (2), 421-433.

Bowen, H. P., Leamer, E. E., Sveikauskas, L., 1987. Multicountry, multifactor tests of the factor abundance theory. The American Economic Review, 791-809.

Brown, G., Micklewright, J., Schnepf, S., Waldmann, R., 2007. International surveys of educational achievement: how robust are the findings? Journal of the Royal Statistical Society: Series A (Statistics in Society) 170 (3), 623-646.

Carneiro, P., Heckman, J., 2003. Human Capital Policy. NBER Working Paper 9495.

Costinot, A., Komunjer, I., 2007. What Goods Do Countries Trade? New Ricardian Predictions. NBER Working Paper 13691.

Costinot, A., Vogel, J., 2009. Matching and Inequality in the World Economy. Mimeo, MIT.

Cuñat, A., Melitz, M. J., 2007. Volatility, Labor Market Flexibility, and the Pattern of Comparative Advantage. NBER Working Paper 13062.

Dahl, G., 2002. Mobility and the return to education: Testing a Roy model with multiple markets. Econometrica, 2367-2420. 
Davis, D. R., Weinstein, D. E., 2001. An account of global factor trade. American Economic Review, $1423-1453$.

De Groot, H., Linders, G., Rietveld, P., Subramanian, U., 2004. The institutional determinants of bilateral trade patterns. Kyklos 57 (1), 103-123.

Feenstra, R., Lipsey, R., Deng, H., Ma, A., Mo, H., Drive, O., 2005. World trade flows: 1962-2000. NBER working paper 11040.

Friesen, J., Krauth, B., 2007. Sorting and inequality in Canadian schools. Journal of Public Economics 91 (11-12), 2185-2212.

Glaeser, E., La Porta, R., Lopez-de Silanes, F., Shleifer, A., 2004. Do institutions cause growth? Journal of Economic Growth 9 (3), 271-303.

Grossman, G. M., 2004. The Distribution of Talent and the Pattern and Consequences of International Trade. Journal of Political Economy 112 (1), 209-239.

Grossman, G. M., Maggi, G., 2000. Diversity and trade. American Economic Review, 1255-1275.

Hanushek, E., Kain, J., Markman, J., Rivkin, S., 2003. Does peer ability affect student achievement? Journal of Applied Econometrics, 527-544.

Heckman, J., Scheinkman, J., 1987. The importance of bundling in a Gorman-Lancaster model of earnings. The Review of Economic Studies, 243-255.

Helpman, E., Itskhoki, O., 2009a. Labor Market Rigidities, Trade and Unemployment. Harvard manuscript.

Helpman, E., Itskhoki, O., 2009b. Labor Market Rigidities, Trade and Unemployment: A Dynamic Model. Mimeo, Harvard University.

Helpman, E., Itskhoki, O., Redding, S. J., 2008a. Inequality and unemployment in a global economy. Mimeo, Harvard University.

Helpman, E., Itskhoki, O., Redding, S. J., 2008b. Wages, Unemployment and Inequality with Heterogeneous Firms and Workers. Mimeo, Harvard University.

Helpman, E., Krugman, P. R., 1985. Market structure and foreign trade. MIT press Cambridge, Mass.

Helpman, E., Melitz, M., Rubinstein, Y., 2008c. Estimating Trade Flows: Trading Partners and Trading Volumes*. Quarterly Journal of Economics 123 (2), 441-487.

Hoxby, C., Building, L., 2000. Peer effects in the classroom: Learning from gender and race variation. NBER working paper 7867.

Iranzo, S., Schivardi, F., Tosetti, E., 2008. Skill dispersion and firm productivity: an analysis with employer-employee matched data. Journal of Labor Economics 26 (2), 247-285. 
James, E., 1993. Why do different countries choose a different public-private mix of educational services? Journal of Human Resources, 571-592.

Kremer, M., 1993. The O-ring theory of economic development. The Quarterly Journal of Economics, 551-575.

Lazear, E., Shaw, K., 2008. The Structure of Wages: An International Comparison. University of Chicago Press.

Levchenko, A. A., 2007. Institutional Quality and Trade. Review of Economic Studies 74 (3), 791819.

Manova, K., 2008a. Credit constraints, equity market liberalizations and international trade. Journal of International Economics 76 (1), 33-47.

Manova, K., 2008b. Credit Constraints, Heterogeneous Firms, and International Trade. Stanford University mimeo.

Nunn, N., 2007. Relationship-Specificity, Incomplete Contracts, and the Pattern of Trade*. The Quarterly Journal of Economics 122 (2), 569-600.

Ohnsorge, F., Trefler, D., 2007. Sorting It Out: International Trade with Heterogeneous Workers. Journal of Political Economy 115 (5), 868-892.

Romalis, J., 2004. Factor proportions and the structure of commodity trade. American Economic Review, 67-97.

Ross, S. A., 1981. Some stronger measures of risk aversion in the small and the large with applications. Econometrica: Journal of the Econometric Society, 621-638.

Stevenson, D., Baker, D., 1991. State control of the curriculum and classroom instruction. Sociology of Education, 1-10.

Stole, L. A., Zwiebel, J., 1996. Intra-firm bargaining under non-binding contracts. The Review of Economic Studies, 375-410.

Takii, K., Tanaka, R., 2009. Does the diversity of human capital increase gdp? a comparison of education systems. Forthcoming Journal of Public Economics.

Tang, H., 2008. Labor Market Institutions, Firm-specific Skills, and Trade Patterns. Mimeo, Hong Kong University of Science and Technology.

Trefler, D., 1993. International factor price differences: Leontief was right! Journal of Political Economy, 961-987.

Trefler, D., 1995. The case of the missing trade and other mysteries. The American Economic Review, 1029-1046.

Tuijnman, A. (Ed.), 2000. Literacy in the Information Age: Final Report of the International Adult Literacy Survey. OECD Paris. 
Woessmann, L., Hanushek, A., Str, P., 2006. Does educational tracking affect performance and inequality? Differences-in-differences evidence across countries. Economic Journal 116 (510), C63-C76. 